Document downloaded from:

http://hdl.handle.net/10251/83648

This paper must be cited as:

Ferrer López, S.; Ruiz Sánchez, T.; Mars, L. (2015). A QUALITATIVE STUDY ON THE ROLE OF THE BUILT ENVIRONMENT FOR SHORT WALKING TRIPS. Transportation Research Part F: Traffic Psychology and Behaviour. 33:141-160. doi:10.1016/j.trf.2015.07.014.

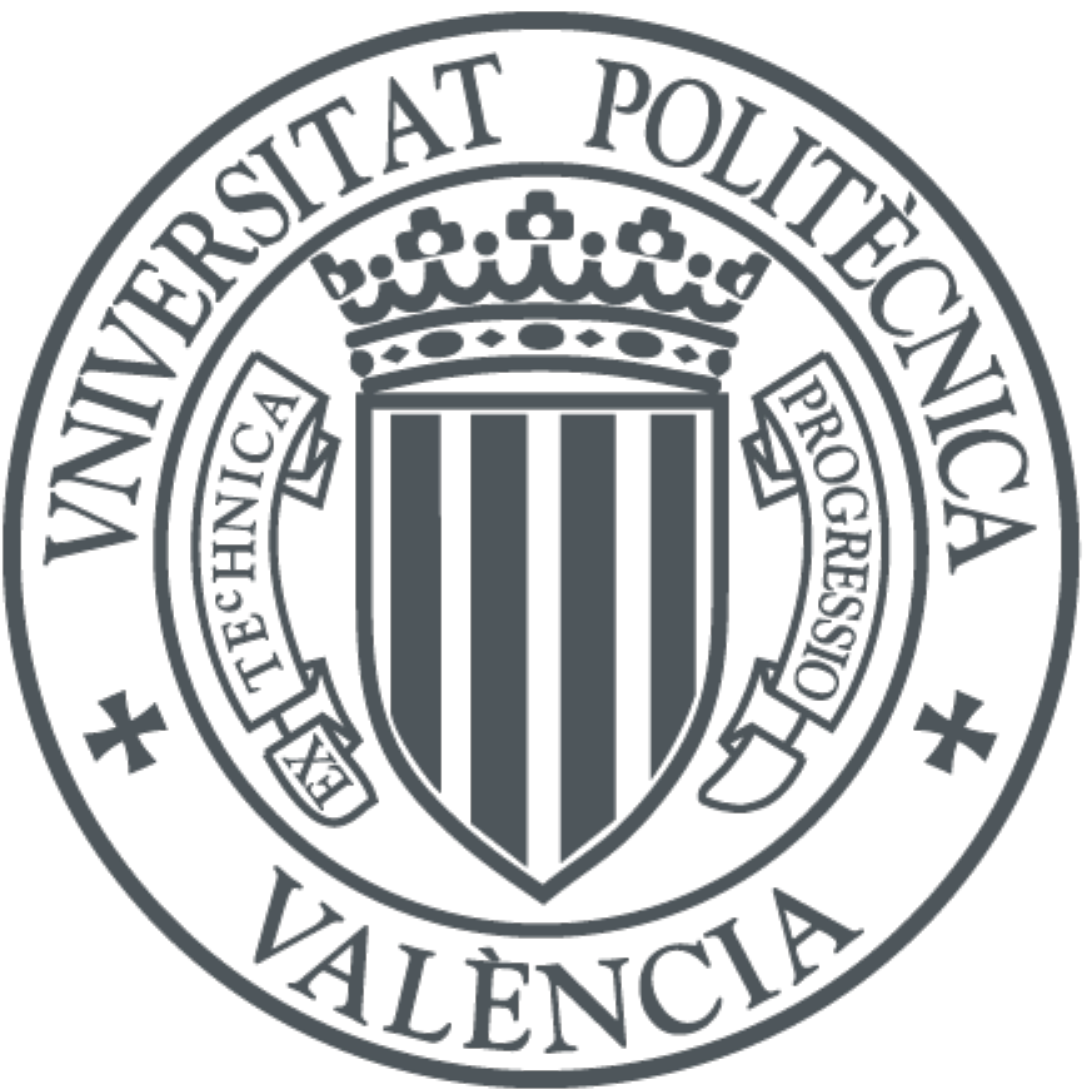

The final publication is available at

http://dx.doi.org/10.1016/j.trf.2015.07.014

Copyright ELSEVIER SCI LTD

Additional Information 


\title{
A qualitative study on the role of the built environment for short walking trips
}

\author{
Sheila Ferrer ${ }^{a}$, *, Tomás Ruiz ${ }^{\mathrm{b}}$ and Lidón Mars ${ }^{\mathrm{c}}$
}

${ }^{a}$ Ph.D. Candidate, Transport Department, School of Civil Engineering, Universitat Politècnica de València, Camino de Vera s/n, 46022 Valencia, Spain

Tel: (+34) 963877365; E-Mail: shferlo@upv.es

b Associate Professor, Transport Department, School of Civil Engineering, Universitat Politècnica de València, Camino de Vera s/n, 46022 Valencia, Spain

Tel: (+34) 963877370; Fax: (+34) 963877370; E-Mail: truizsa@tra.upv.es

${ }^{c}$ Researcher, Social Psychology Department, Faculty of Psychology, Universitat de València, Avenida Blasco Ibáñez 13, 46010 Valencia, Spain

Tel: (+34) 963983940; Fax: (+34) 963864668; E-mail: $\underline{\text { m.lidon.mars@uv.es }}$

* Corresponding author 


\begin{abstract}
The present study uses a qualitative approach with the aim to identify built environmental factors influencing short walking distances for transportation among adults (18-65 years), with special attention to micro-scale attributes. Three focus groups were held in Valencia (Spain) and conducted with participants who undertook, at least once a week, one short non-shopping trip in any travel mode (were "short trip" is defined as less than 30-45 minutes walking distance). A thematic analysis of the data was performed and six categories of factors emerged related to the built environment. Factors were also classified as either barriers to walking, or secondary factors related to the attractiveness of the walking experience and the pedestrian route choice. Results show that factors related to safety from crime are the most deterrent to walking (absence of people and poor street lighting), along with the availability of car parking at destination for car users. Crossing large avenues and roundabouts in Valencia can be a deterrent to walking because of the high density of pedestrian traffic signals with a poor coordination, leading to long crossing waiting times. Secondary factors such as wide sidewalks, the presence of trees, and low traffic volume roads were mentioned by almost all participants. Our findings suggest that sidewalk width may not only influence pedestrian route choice but can be a barrier to walking. Focus groups also revealed that sidewalk cafes and bollards were seen as physical obstacles by some participants.
\end{abstract}

Keywords: built environment, focus group, walking, pedestrian, short trip, mode choice 


\section{Introduction}

Walking is an environmentally friendly travel mode and one of the alternatives to individual conventional transportation. Promoting sustainable travel behavior is among the objectives of the European Union to reduce $\mathrm{CO}_{2}$ emissions from transportation (EC, 2011). Active transportation is also related to health: countries where active transportation is most common have the lowest obesity rates (Bassett et al., 2008).

Many studies have provided evidence of the association between neighborhood design and active transportation. Some reviews identify how researchers in transportation and urban planning (Hodgson et al., 2004; Hof, 2010; Saelens et al., 2003; Saelens \& Handy, 2008) and in population health (Owen at al., 2004) are examining potential environmental determinants of transport-related walking.

Most studies have focused on the meso-scale (or neighborhood scale) built environmental factors when examining the correlation with walking, such as residential density, land use mix, street connectivity, etc. However, meso-scale measures in general have drawbacks for capturing micro-scale (or street level) built environment characteristics, such as the presence of trees, the width of the sidewalks, and the quality of the streets (Kim et al., 2014). The current study examines macro and micro factors of the built environment determining the decision to walking for transportation, and also a set of factors influencing the individual perception for a pleasant walking trip. Special attention is given to micro-scale built environment factors, as the roles of micro-scale elements are not well understood due to limited data availability (Lee et al., 2013). A qualitative approach based on focus groups is used with the aim to identify new environmental factors and to collect more detailed data on previously studied factors.

The following section presents a review of the related literature. This is followed by the description of the methods used to conduct the study and the main results. The paper ends with a discussion, conclusions, and limitations and further research.

\section{Literature review}

\subsection{The built environment}

Davison \& Lawson (2006) defined the built or physical environment as objective and perceived characteristics of the physical context in which people spend their time (e.g., home, neighborhood, school) including aspects of urban design (e.g., presence and structure of sidewalks), traffic density and speed, distance to and design of venues for physical activity (e.g., playgrounds, parks and school yards), crime, safety and weather conditions.

The literature review of our study considers objective and perceived characteristics of the physical environment related to walking, according to the definition by Davison \& Lawson (2006). 


\subsection{Walking for transportation}

Some studies have pointed out the importance of distinguishing between travel for utilitarian purposes (e.g. walking to work, etc.) and travel for recreation (e.g., go to the gym, to a park, to the beach, strolling, etc.) as the factors of the built environment that influence these two categories of travelling differ significantly (Cao et al. 2006; GilesCorti \& Donovan, 2002; Saelens \& Handy, 2008; among others). We are only interested in built environmental factors influencing walking to reach a destination, also defined as walking for transportation. In our study, trips related to recreational purposes (e.g., go to the gym, to the swimming pool, etc.) except strolling are considered walking for transportation as well.

\subsection{The built environment and walking for transportation}

\subsubsection{Quantitative approaches}

The relationship between walking among adults and the built environment using quantitative approaches has been explored by means of objective and perceived measures of the factors of interest. The first group includes studies that use objective measures of the built environment characteristics at a micro-level or larger scale around individuals' residence (Cao et al, 2009; Clark et al., 2014; Greenwald \& Boarnet, 2001; Frank et al., 2007; Lovasi et al., 2013; Saelens \& Handy, 2008; Shriver, 1997; Van Dyck, 2010). Findings by Shriver (1997) suggest that walking-activity patterns are influenced by street connectivity, mixed use areas, and outdoor seating. Greenwald \& Boarnet (2001) results suggest that regardless of the effects that land use has on individual non-work walking trips, the impacts take place at the neighborhood level. Results provided by Cao et al. (2009) show that mixed land uses, the availability of walking infrastructures, aesthetics quality and social context are associated with walking for transportation. Van Dyck et al. (2010) found that living in a high-walkable neighborhood was associated to more walking and cycling for transportation.

Similarly, objective measures of the built environment have been studied to explain their influence on physical activity and non-motorized travel (Cervero \& Kockelman, 1997; Badland \& Schofield, 2005; Handy \& Clifton, 2001; Rodriguez \& Joo, 2004). For example, Cervero \& Kockelman (1997) found that density, land-use diversity and pedestrian-oriented designs reduce automobile trip rates and encourage non-auto travel modes. Rodriguez \& Joo (2004) found that the presence of sloping terrain decreases the attractiveness of walking and cycling. In addition, some studies have developed trip mode choice models incorporating residential environmental characteristics as explicative factors (Kim \& Ulfarsson, 2008; Lee et al., 2014; Singleton \& Wang, 2014). Singleton \& Wang (2014) suggested that higher densities of more comfortable facilities for walking (low-traffic streets), higher densities of traffic signals and traffic calming installations were associated with increased levels of walking. 
The second group of studies examines the relationship between walking and perceptions of attributes of the local neighborhood (Craig et al., 2002; Panter et al., 2014). Craig et al. (2002) modeled the relationship between walking to work and an environment score based on 18 neighborhood characteristics, and found that with the exception of visual interest and aesthetics, each neighborhood characteristic was correlated with walking (e.g., safety from crime, traffic, etc.). Panter et al. (2014) found that the proportion of car trips increased for commuters who reported that the route became less pleasant to walk or more dangerous to cross the road.

Other studies have simultaneously considered objective and subjective assessments on the neighborhood characteristics to understand how they explain walking (Cao et al., 2006; Foster et al., 2012; Hoehner et al., 2005; Walton \& Sunseri, 2006). Foster et al. (2012) found that fear was associated with lower odds of transport-related walking.

Finally, some studies have focused on the understanding of factors influencing the walkability of the pedestrian environment (Ewing \& Handy, 2009; Kelly et al., 2011; Leslie et al., 2005; Van Dyck et al., 2010). Kelly et al. (2011) found that pedestrians consider important both traffic volume and the priority of vehicles to pedestrians. In addition, they also identified some of the factors improving pedestrian quality, such as clean pavements, connectivity and a perception of safety.

\subsubsection{Qualitative approaches}

Different qualitative methodologies have been used to study how built environmental factors are related to walking for transportation. For example, Cauwenberg et al. (2012) used walk-along interviews with 57 adults (over 65) to find out the perceived environmental factor influencing walking for transportation. Some studies used focus groups to research on neighborhood factors and active aging (Grant et al., 2010; Michael et al., 2006; Nathan et al., 2013). Other studies using focus groups are linked to children (Loitz \& Spencer-Cavaliere, 2013), or young people and older adolescents (Lake \& Townshend, 2013; Simons et al., 2013).

In a qualitative exploratory study, Locket el al. (2005) used focus-groups and a photovoice technique to examine environmental barriers and facilitators related to walking in 13 seniors citizens in Ottawa (Canada). Photo-voice is a technique in which photographs taken by community members are used to facilitate discussion between community members (Lockett et al., 2005; Wang \& Burris, 1997). Similarly, Gallagher et al. (2005) used focus-groups and a photo-voice methodology to identify the most important factors of the neighborhood environment that encourage or discourage walking in older, urban African Americans. Middleton (2009) used in-depth interviews and experiential walking photo diaries to explore the spatial and temporal context of walking. 
To the best of our knowledge, this is the first study using focus groups to identify factors of the built environment influencing walking for transportation in adults with a high level of detail. All previous research using focus groups has focused on a particular group of study (children, adolescents and older adults), and no other research using this qualitative approach has simultaneously focused on adults and in walking for transportation with such level of detail. We consider a qualitative research method the most appropriate for exploring the wide range of factors involved.

Appendix A provides a review of factors that have been found related to walking for transportation in adults (18-65 years) in the literature. Studies focused on children, adolescents and older adults are excluded as these groups present specific needs, different from the population of our study. In addition, as we are only interested in walking to reach a destination (walking for transport), Appendix A does not include any factor related to walking for recreation in the literature, as this category includes strolling. Thus, Appendix A summarizes studies using different methodologies (e.g., qualitative, quantitative, etc.), and with different aims, except those associated with walking route choice. For quantitative studies, only factors significantly correlated with walking for transportation have been included. Some difficulties have emerged when dealing with results provided by qualitative studies. First, as a categorization of factors by level of importance was not available for most qualitative studies, all factors cited in the text have been included. Second, some qualitative studies have focused on walking in general, and after a thorough examination of the text, only those results linked to walking for transportation were included, excluding findings related to strolling.

\section{Methodology}

\subsection{The research setting: the region of Valencia}

Valencia is Spain's third largest city (0.76 million inhabitants), with a metropolitan population of 1.6 million (Ajuntament de València, 2013a). The city of Valencia has a radial structure with a historic centre with mixed land uses and narrow streets, and districts around the city centre with long straight streets, in a grid pattern crossed by wide avenues with high traffic volumes. In terms of travel behavior, trips within the city of Valencia (both origin and destination in the city) are characterized by the following mode shares: walking and cycling trips $(53 \%)$, car trips $(23.6 \%)$ and trips by public transport (23.4\%) (Ajuntament de València, 2013). The travel behavior in the metropolitan area of Valencia is characterized by a higher predominance of the use of private car, however, walking trips still represent the highest mode share: walking and cycling trips $(44.9 \%)$, car trips $(31.9 \%)$ and public transport $(23.2 \%)$ (Ajuntament de València, 2013b).

\subsection{Recruitment}

Three focus groups were held with a total of 23 participants: one pilot focus group and two main focus groups. The pilot focus group was held with graduated civil engineers 
and people currently employed at the School of Civil Engineering aged 28-32 years. On the other hand, potential participants of the two main focus groups were facilitated by students of Civil Engineering at Universitat Politècnica de València (Spain), who recruited some friends and relatives. To be eligible to participate in the main focus groups, participants had to be over 30, make at least one short non-shopping trip in any travel mode once a week (were "short trip" was defined as less than 30-45 minutes walking distance), have no health problem that limits walking, not studying or working at Universitat Politècnica de València, and be willing to participate in a video-taped focus group. As participants in main focus groups were facilitated by students of Civil Engineering, an age criteria was established to avoid the recruitment of very young participants only (i.e. friends of the students), which would introduce a significant bias in the results of the study. To reduce familiarity between participants in the focus groups and ensure a greater anonymity, no more than two participants recruited by the same student were together in a focus group. Furthermore, none of the students participated in the focus groups.

Potential participants filled out a recruiting questionnaire including socio-demographic characteristics (age, gender, address), information on a short non-shopping trip undertaken at least once a week (location of the origin and destination of the trip, travel mode, activity at destination and whether respondent returns to the origin) and answered questions related to their appropriateness to participate in a focus group (how they behave in a group context and with people they have just met, etc.). Trips provided by participants were verified using "Google Maps" as a proxy to check if they were short trips. Based on the questionnaire results, most suitable participants were selected to participate in the focus groups. They were contacted by phone and asked about the most habitual travel modes used for urban trips. Participants in the main focus groups were homogenous according to age. In addition, all groups consisted of car users, pedestrians, cyclists and public transport users for short trips. Independently of the mode of transportation chosen for the short trip provided, regular car users were about half of the participants of each focus group.

The preliminary recruiting questionnaire and discussion guide used in the pilot focus group, only included small changes compared to those utilized in the main focus groups; thus, the data collected from the three focus groups is part of the analysis.

\subsection{Focus groups}

Pilot and main focus groups were conducted in March 2014 with a total of 23 participants (9 male, 14 female) in Valencia (Spain) (Table 1). 17 out of 23 participants were residents in the city of Valencia, and the rest were residents of different municipalities of the region of Valencia: Paterna $(5 \mathrm{~km}$ from the city of Valencia), Burjasot $(7 \mathrm{~km})$, Moncada $(13 \mathrm{~km})$, and Játiva $(63 \mathrm{~km})$. In addition, 11 out of 23 participants stated to use car for urban trips as first or second choice for transportation. 
The number of participants in each focus group varied from 7-9, following Krueger \& Casey (2000) suggestion of focus groups between six and eight participants, as smaller focus groups show greater potential. All focus groups were conducted in Spanish and lasted approximately 90 minutes, as this is the average focus group duration (Morgan, 1996). The first author was the moderator of the three focus groups and was aided by a research assistant, as suggested by Asbury (1995). Participants, moderator and research assistant were seated in a circle without a table in the middle to facilitate the discussion.

The moderator followed a semi-structured discussion guide developed for the study in consultation with the research team and followed recommendations for focus groups methodology (Krueger \& Morgan, 1994; Morgan, 1996). In order to ensure everyone to participate equally in the discussion, the research assistant helped the moderator in the task of identifying less participative individuals, and the moderator solicited answers from those individuals. The first author observed that no new concepts were discussed during the third focus group, thus data saturation was reached. Participants were rewarded for their contribution.

Table 1- Focus groups characteristics

\begin{tabular}{|c|c|c|c|c|c|c|}
\hline Focus group & Description & $\begin{array}{l}\text { Number of } \\
\text { participants }\end{array}$ & $\begin{array}{l}\text { Participants' } \\
\text { Reference }\end{array}$ & $\begin{array}{c}\text { Range of } \\
\text { age* }\end{array}$ & Male & Female \\
\hline $\begin{array}{l}\text { Pilot Focus Group } \\
\text { (FG0) }\end{array}$ & $\begin{array}{l}\text { Employees at the } \\
\text { School of Civil Eng. }\end{array}$ & 7 & P1-P7 & $28-32$ & 4 & 3 \\
\hline $\begin{array}{l}\text { Focus Group } 1 \\
\text { (FG1) }\end{array}$ & $\begin{array}{l}\text { Relatives and } \\
\text { friends of students } \\
\text { of Civil Eng. }\end{array}$ & 9 & P8-P16 & $40-60 *$ & 4 & 5 \\
\hline $\begin{array}{l}\text { Focus Group } 2 \\
\text { (FG2) }\end{array}$ & $\begin{array}{l}\text { Relatives and } \\
\text { friends of students } \\
\text { of Civil Eng. }\end{array}$ & 7 & P17-P23 & $40-60 *$ & 1 & 7 \\
\hline
\end{tabular}

*For Focus Group 1 and 2, only the range of age of each participant was known.

In the focus group introduction, the moderator welcomed participants, reminded them of the purpose of the group and set ground rules. Participants were encouraged to express their opinions freely, and were informed that all opinions were equally valuable. Before asking the first question, an icebreaker activity was carried out using balloons to increase comfort of participants and create a pleasant environment.

For the design of the focus group interview questions, results provided by Mackett (2003) on the main reasons why people use their cars for short trips, and Walton \& Sunseri (2007) about the impediments to walking as a mode choice, were considered to avoid questions leading to common answers and to focus the group discussion on the particular topic of interest. The main specific reasons identified by Mackett (2003) for driving the car were: carrying heavy goods (for shopping, in most cases), taking children to school, lack of time, needing the car for a further trip, long trip, convenience, bad weather or nightfall. Thus, the aim of the first questions (3-5, in Table 2) was to identify the individual walkable distance in minutes the participant is willing to walk to 
a destination and to obtain most commonly referred factors influencing walking (lack of time, bad weather, etc.). After these introductory questions, we started discussing the key questions (6-14), which were related to the built environment factors influencing walking. Questions 9 and 10 were made while showing participants a selection of 6-8 photographs of streets of Valencia (Figure 1). Photographs of some streets of Valencia were selected from Google Street View or other sources based on the following criteria: to represent different built environments, to show as many number of elements of the built environment as possible, taken on a sunny day and from the pedestrian point of view of a street, if possible. It is important to mention that participants were told to think in short walking trips to a single destination, to avoid trips with multiple purposes with a higher complexity and tendency to be performed using motorized travel modes. Table 2 presents a summary of the discussion guide.

At the end of each focus group, participants were asked to fill out a final satisfaction questionnaire to assess their level of comfort during the icebreaker and the focus group discussion, and to check if they had found difficulties in understanding any of the questions. All participants reported to be very comfortable during the focus group discussion, meaning that they felt free to express their own opinions. In addition, the high satisfaction level of participants revealed that 90 minutes was an effective duration: a shorter duration would not provide the information needed and any longer would affect participants' concentration and interest.
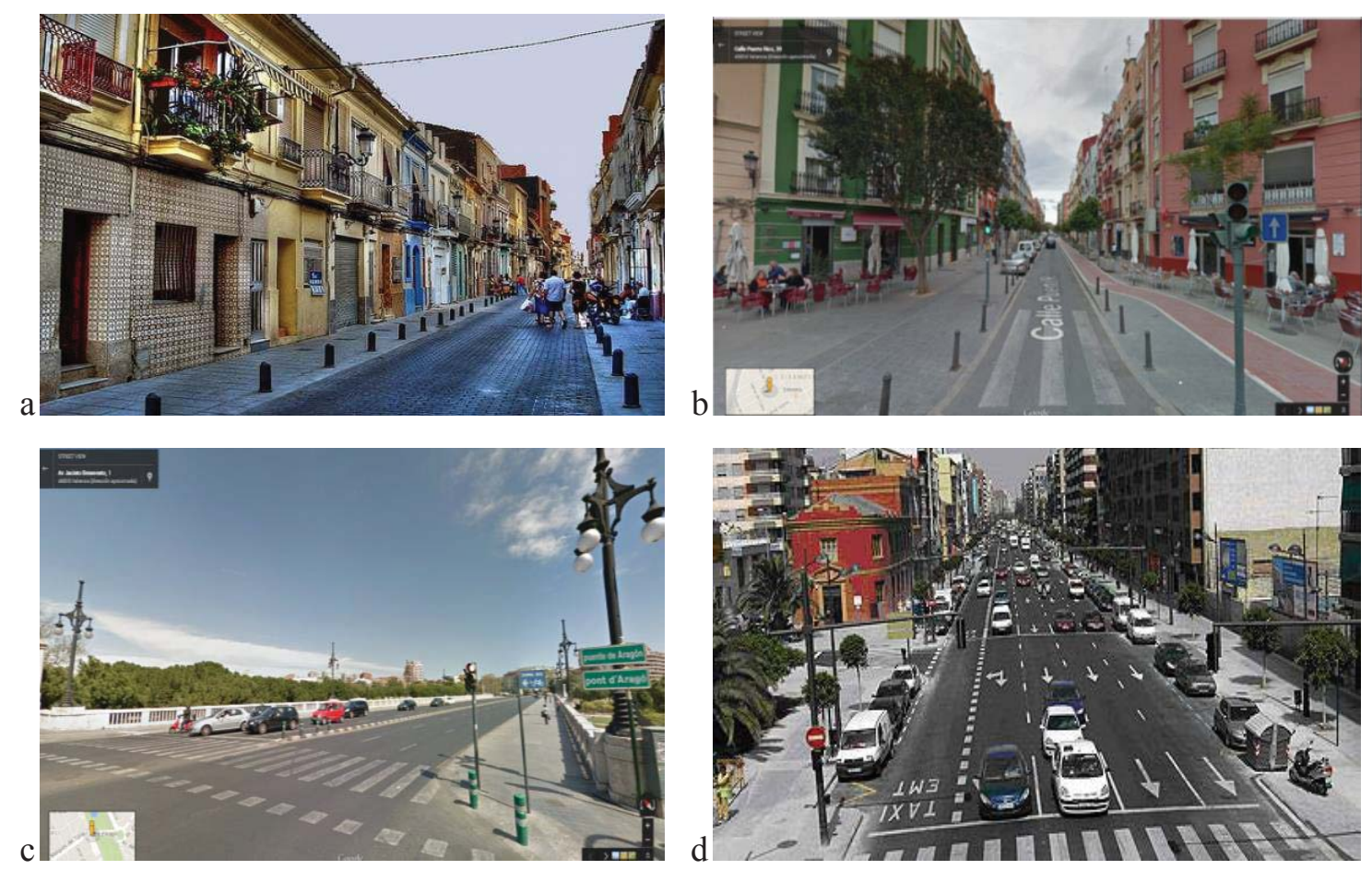

Figure 1- Examples of four photographs shown in the focus groups. Figure 1a (source: http://www.deverdaddigital.com/pagArticle.php?idA=9749) Figure $1 \mathrm{~b}$ and 1c were extracted from Google Street View (accessed on 20 $0^{\text {th }}$ October 2014), Figure 1d (source: http://www.lovevalencia.com/calles/avenida-del-puerto). 
Table 2- Semi-structured discussion guide

\begin{tabular}{|c|c|c|c|}
\hline $\begin{array}{l}\text { Question } \\
\text { type }\end{array}$ & Objective & Question & $\begin{array}{c}\text { Timing } \\
(\min )\end{array}$ \\
\hline Opening & Welcome participant & objective of the focus group and set ground rules. & 5 \\
\hline \multirow{4}{*}{ Introduction } & Icebreaker activity & 1. Tell us your name and your favorite travel mode & 5 \\
\hline & Start discussion & $\begin{array}{l}\text { 2. How have your travel habits changed as a consequence } \\
\text { of the financial crisis? }\end{array}$ & 5 \\
\hline & $\begin{array}{lr}\text { Identify } & \text { personal } \\
\text { maximum } & \text { and } \\
\text { minimum } & \text { walkable } \\
\text { distance } & \end{array}$ & $\begin{array}{l}\text { 3. How far are you willing to walk to go to a place before } \\
\text { considering a different travel mode? Think in minutes } \\
\text { walking (maximum walkable distance) } \\
\text { 4. Which is the minimum distance (in minutes) where } \\
\text { walking is automatically chosen? (minimum walkable } \\
\text { distance) }\end{array}$ & 5 \\
\hline & $\begin{array}{l}\text { Common factors } \\
\text { influencing travel } \\
\text { mode choice for } \\
\text { short trips }\end{array}$ & $\begin{array}{l}\text { 5. What things influence the travel mode choice for short } \\
\text { trips without carrying heavy goods? }\end{array}$ & 5 \\
\hline \multirow{5}{*}{ Key topic } & $\begin{array}{l}\text { Built environmental } \\
\text { factors influencing } \\
\text { the travel mode } \\
\text { choice for short } \\
\text { trips }\end{array}$ & $\begin{array}{l}\text { 6. Imagine you have to go to a place from home and later } \\
\text { you come back. You are not carrying heavy goods and the } \\
\text { weather is fine. Which factors of the built environment } \\
\text { influence your decision to walk? }\end{array}$ & 5 \\
\hline & $\begin{array}{l}\text { Factors influencing } \\
\text { the walking } \\
\text { experience }\end{array}$ & $\begin{array}{l}\text { 7. Imagine you have to walk for transportation, your } \\
\text { maximum walkable distance, the weather is fine and you } \\
\text { are not carrying heavy goods. What things of the walking } \\
\text { route would make it walking more attractive? } \\
\text { 8. Imagine you only have to walk } 5 \text { minutes for } \\
\text { transportation, the weather is optimum and you are not } \\
\text { carrying heavy goods. What things of the walking route } \\
\text { would make it walking unattractive? } \\
\text { 9. Pictures of streets of Valencia are shown. Imagine you } \\
\text { are walking for transportation along that street, which } \\
\text { things you see are attractive? Which things make the walk } \\
\text { unattractive? } \\
\text { 10. Any of those things you consider unpleasant can be an } \\
\text { impediment to walking and make you choose an } \\
\text { alternative travel mode? }\end{array}$ & 35 \\
\hline & $\begin{array}{l}\text { Factors related to } \\
\text { safety from traffic }\end{array}$ & $\begin{array}{l}\text { 11. While walking, in which moments do you feel you } \\
\text { could experience an accident and which risks do you find? }\end{array}$ & 5 \\
\hline & Barriers to walking & $\begin{array}{l}\text { 12. Which things in the environment that you see, hear, } \\
\text { smell or experience during a walking route, can influence } \\
\text { your travel mode choice? } \\
\text { 13. Do any of those factors influence the walking route } \\
\text { you choose? }\end{array}$ & 5 \\
\hline & $\begin{array}{l}\text { Influence of the } \\
\text { purpose of the trip }\end{array}$ & $\begin{array}{l}\text { 14. Does the built environment influence similarly the } \\
\text { travel mode you choose for trips to work or other types of } \\
\text { trips? }\end{array}$ & 5 \\
\hline Ending & $\begin{array}{l}\text { Identify any } \\
\text { additional factor not } \\
\text { discussed }\end{array}$ & $\begin{array}{l}\text { 15. Anything else influencing the travel mode you choose } \\
\text { for short trips that we should have talked about? }\end{array}$ & 5 \\
\hline
\end{tabular}




\section{4. Data analysis}

\subsubsection{Thematic analysis}

We conducted a thematic analysis (Attride-Stirling, 2001). Thematic analysis is a method for identifying, analyzing, and reporting patterns (themes) within data and is used to structure our understanding of the data, following Braun \& Clarke's (2006) guidelines. In order to conduct a thematic analysis, the first step is the transcription of the verbal data recorded in the videos. All video recordings were transcribed by the first author, providing an excellent way to start familiarizing the data (Riessman, 1993). It is reasonable to transcribe only as much as required by the research question and nothing else (Strauss, 1987). The material also required paraphrasing to transform the passages transporting content into a coherent level of language and a grammatical short version (Flick, 2014). The paraphrasing task was performed while transcribing. Although the main source of data analysis is the recorded spoken language derived from the focus groups, capturing the non-verbal communication adds a valuable dimension (Rabiee, 2004). Following Onwuegbuzie et al. (2009) recommendations, in addition to transcribing the verbatim statements made by focus group participants, information on how many members agreed was included. Not only verbal agreement such as "I agree" or "Yes" was considered, but also nonverbal agreement such as nodding one's head.

\subsubsection{Coding process}

For the coding process, a theoretical thematic analysis is conducted, where initial codes are based on prior research and existing literature, and additional codes are suggested from the participants' comments (Morgan \& Krueger, 1998). In our case, initial codes are based on existing literature and themes identified by Cauwenberg et al. (2012) and Schneider (2013). The final coding frame was discussed with the second author of the paper. The qualitative research software QSR NVivo 10 was used to facilitate coding and data analysis.

The coding process was performed at two levels: to identify factors explicitly cited by focus groups' participants, which influenced walking or not as a mode choice (barriers to walking); and to identify factors influencing how pleasant is the walking experience (secondary factors).

\subsubsection{Data interpretation}

Qualitative data interpretation is reinforced by quantitative counts of the participants discussing certain factors, following Krueger's criteria (1994) of including frequency and extensiveness of comments. This criterion was also previously used by Cauwenberg et al. (2012) and Simons et al. (2013). Thus, when a factor was discussed by less than $25 \%$, we defined it "few", for between $25 \%$ and $50 \%$, we defined it "some", for 
between $50 \%$ and $75 \%$, we defined it "a lot of" and for more than $75 \%$ of the participants, we defined it "almost all" in the results' description.

\section{Results}

Questions 3 and 4 were aimed at identifying participants' walkable distances. In terms of the maximum distance willing to walk for transportation, it differed between participants and ranged from 10 to more than 60 minutes. Participants reporting car use for urban trips as first or second travel choice were less willing to walk for more than 10-20 minutes, while those using other travel modes as first or second travel choice stated more frequently to be willing to walk for transport more than 20 minutes (see Table 3). Despite the maximum distances participants were willing to walk for transportation, some of them agreed in identifying a minimum walkable distance below 10-20 minutes where trips were very likely to be undertaken walking.

Table 3- Urban travel behavior of focus groups participants

\begin{tabular}{lccc}
\hline Transportation modes for urban trips & $\begin{array}{c}\text { Number of } \\
\text { participants }\end{array}$ & $\begin{array}{c}\text { Maximum distance willing to } \\
\text { walk for transportation }\end{array}$ \\
\cline { 3 - 4 } Car as first or second choice & 11 & 6 & 5 \\
\hline Other modes as first or second choice & 12 & 7 & 11 \\
\hline Total & 23 & & 16 \\
\hline
\end{tabular}

Qualitative data analysis of answers to questions 5-15 revealed five main categories of built environmental factors influencing walking for transportation: safety from crime (street lighting, other people, cleanliness, etc.), traffic safety (traffic volume, traffic speed, crossing waiting times, etc.), walking facilities (sidewalk width, obstacles, etc.), aesthetics (presence of green elements, buildings, noise, etc.), convenience and other perceptions (availability of car parking, hills and pedestrian volume, open and wide spaces and length perception).

According to the importance of each factor in influencing walking for transportation, it could be classified as a barrier to walking for transportation or as a secondary factor influencing the walking experience. The criterion for classifying a factor as a barrier or as a secondary factor was the following:

- Barrier/deterrent to walking for transportation: factor that by itself explicitly influences the decision to walk for at least one person in the focus groups

- Secondary factor influencing walking: factor that is not mentioned as a barrier to walking, but is related to the pleasantness or comfort of the walking experience and/or explicitly influences the walking route choice

Table 4 includes all factors influencing walking for transportation found in our study. 
Table 4- Factors influencing walking for transportation in adults

\begin{tabular}{|c|c|c|c|c|c|}
\hline \multirow{2}{*}{ Factors } & \multirow[b]{2}{*}{ Type } & \multicolumn{4}{|c|}{$\%$ of participants } \\
\hline & & $\begin{array}{c}\text { For almost all } \\
(75-100 \%)\end{array}$ & $\begin{array}{c}\text { For a lot of } \\
(50-75 \%)\end{array}$ & $\begin{array}{l}\text { For some } \\
(25-50 \%)\end{array}$ & $\begin{array}{c}\text { For a few } \\
(0-25 \%)\end{array}$ \\
\hline \multirow[b]{2}{*}{$\begin{array}{c}\text { Safety from } \\
\text { crime }\end{array}$} & B & - & $\begin{array}{l}\text { - Poor street } \\
\text { lighting* (-) }\end{array}$ & $\begin{array}{l}\text { - Absence of } \\
\text { people*(-) }\end{array}$ & - \\
\hline & $\mathrm{S}$ & - & - & - & $\begin{array}{l}\text { - Crossing bridges at } \\
\text { night }(-) \\
\text { - Cleanliness }(+) \\
\text { - White LED lights (+) } \\
\text { - Graffiti (-) } \\
\text { - Closed shops (-) } \\
\text { - Wall publicity (-) } \\
\text { - Vagrants (-) } \\
\text { - Crossing parking } \\
\text { lots }(-)\end{array}$ \\
\hline \multirow[b]{2}{*}{ Traffic safety } & B & - & $\begin{array}{l}\text { Long crossing } \\
\text { waiting times }{ }^{* 1}(-)\end{array}$ & $\begin{array}{l}\text { - High intersection } \\
\text { density*1 (-) }\end{array}$ & - \\
\hline & S & $\begin{array}{l}\text { - Traffic } \\
\text { volume (-) }\end{array}$ & $\begin{array}{l}\text { - Pedestrian } \\
\text { zone (+) } \\
\text { - Negative bicycle } \\
\text { users' behavior (-) } \\
\text { - Negative car } \\
\text { users' behavior (-) } \\
\text { - Street width (+/-) }\end{array}$ & $\begin{array}{l}\text { - Number of lanes (-) } \\
\text { - Separation of cycle } \\
\text { lane (+) } \\
\text { - Poor coordination } \\
\text { between adjacent } \\
\text { pedestrian traffic } \\
\text { signals in avenues } \\
\text { and roundabouts (-) } \\
\text { - High traffic speed (-) } \\
\text { - Crossing points with } \\
\text { bike lanes (-) } \\
\text { - Separation from } \\
\text { traffic at bridges (+) } \\
\text { - Pedestrian } \\
\text { countdown at traffic } \\
\text { signals (+) } \\
\text { - Pedestrian crossings } \\
\text { with possibility of } \\
\text { turning vehicles (-) }\end{array}$ & $\begin{array}{l}\text { - Number of lanes to } \\
\text { cross }(-) \\
\text { - Audible pedestrian } \\
\text { traffic signals }(+) \\
\text { - Pedestrian crossing at } \\
\text { roundabouts }(-)\end{array}$ \\
\hline \multirow[b]{2}{*}{$\begin{array}{l}\text { Walking } \\
\text { facilities }\end{array}$} & B & - & - & - & $\begin{array}{l}\text { - Poor/ lack of } \\
\text { sidewalks *(-) }\end{array}$ \\
\hline & S & $\begin{array}{l}\text { - Wide } \\
\text { sidewalks }(+)\end{array}$ & $\begin{array}{l}\text { - Obstacles on } \\
\text { sidewalks (-) }\end{array}$ & - & $\begin{array}{l}\text { - Accessibility/ } \\
\text { ramps (-) } \\
\text { - Sidewalks quality }(+) \\
\text { - Trees providing } \\
\text { shade in summer }(+)\end{array}$ \\
\hline \multirow[b]{2}{*}{ Aesthetics } & B & - & - & - & - Smell* (-) \\
\hline & S & $\begin{array}{l}\text { - Green } \\
\text { elements }(+)\end{array}$ & $\begin{array}{l}\text { - Noise (-) } \\
\text { - Architecture (+) }\end{array}$ & $\begin{array}{l}\text { - } \text { Presence of } \\
\text { people }(+) \\
\text { - Smell-pollution }(-) \\
\text { - Interesting views }(+) \\
\text { - Cleanliness }(+) \\
\text { - Shops }(+) \\
\text { - Dog fouling }(-) \\
\text { - Benches }(+) \\
\text { - Natural light }(+)\end{array}$ & $\begin{array}{l}\text { - } \text { Continuous walls(-) } \\
\text { - } \text { Maintenance (+) } \\
\text { - Variety of colors, } \\
\text { shapes (+) } \\
\text { - Homogeneity, } \\
\text { criteria, order (+) } \\
\text { - Low buildings (+) } \\
\text { - Animals (-) } \\
\text { - Garbage collection (-) } \\
\text { - Bad drainage }(-) \\
\text { - Other urban furniture } \\
\text { - }) \\
\text { - Sidewalk cafes }(+) \\
\text { - Graffiti }(+)\end{array}$ \\
\hline
\end{tabular}


Table 4 (Continued)

\begin{tabular}{|c|c|c|c|c|c|}
\hline \multirow{2}{*}{ Factors } & \multirow[b]{2}{*}{ Type } & \multicolumn{4}{|c|}{$\%$ of participants } \\
\hline & & $\begin{array}{c}\text { For almost all } \\
(75-100 \%)\end{array}$ & $\begin{array}{c}\text { For a lot of } \\
(50-75 \%)\end{array}$ & $\begin{array}{l}\text { For some } \\
(25-50 \%)\end{array}$ & $\begin{array}{c}\text { For a few } \\
(0-25 \%)\end{array}$ \\
\hline \multirow{2}{*}{$\begin{array}{c}\text { Convenience } \\
\text { and other } \\
\text { perceptions }\end{array}$} & B & - & $\begin{array}{l}\text { - Available car } \\
\text { parking at } \\
\text { destination (-) } \\
\text { ( } 75 \% \text { of habitual } \\
\text { car users) }\end{array}$ & - & - Hills* (-) \\
\hline & $\mathrm{S}$ & - & - & - & $\begin{array}{l}\text { - High pedestrian } \\
\text { volumes (-) } \\
\text { - Open, wide spaces } \\
(+) \\
\text { - Long avenues (-) }\end{array}$ \\
\hline
\end{tabular}

B: barrier to walking for transportation, $\mathrm{S}$ : secondary factor

$(+)$ or $(-)$ according to the positive or negative effect of the factor towards walking

* factors identified as barriers to walking by all participants mentioning it

*1 factors identified as barriers to walking by some participants mentioning it but not by all

Next, results are shown according to the level of importance of the factors: first, barriers, and then, secondary factors. The main categories are identified with all of the factors related to each category. Findings are supported by comments made during the focus groups, conveniently identified in the following way: participant's most habitual travel modes for urban trips in general (habitual car user, pedestrian and public transportation user, etc.), age range (thirties, etc.), participant reference (P1 to P23, as identified in Table 1), and focus group number (F0 to F2, as identified in Table 1).

\subsection{Barriers to walking for transportation}

\subsubsection{Safety from crime}

\subsubsection{Street lighting and absence of people}

For almost all participants, the fear of crime is the strongest deterrent to walking for transportation for a short trip, particularly at night. There were some differences in the perceptions of safety according to gender: for all female (14/14), the feeling of insecurity constitutes a barrier to walking, and for some male (4/9) it is a deterrent. A poor lighting (14/18), the absence of people (9/18) and walking along an area perceived as conflictive (3/18), were the main reasons for not walking for transportation. Referring to the street lighting, a female participant mentioned:

- "The area is also important for me, and a lot of light, and if it is at night, a lot of street lighting" (pedestrian, fifties, Participant 12-P12, Focus Group 1-FG1)

For example, a female participant talked about the absence of people at night: 
- "Even in pedestrian zones, that encourage walking, as there are fewer people, you don't see cars, then they are less crowded... then you don't feel like walking, because you perceive the route as unsafe [...] mainly at certain hours at night, and if all of these factors coincide: it is at night, it is a pedestrian zone, not a lot of people around...I would opt for a different travel mode" (car user and pedestrian, late twenties, $\mathrm{P} 7, \mathrm{FG} 0$ ).

Two female participants spontaneously started talking about the street lighting color. They agreed that white LED lights were brighter, increasing their level of safety from crime at night, compared to yellow lights.

- "In Torrente (town close to Valencia) the street lighting is white, not yellow like in Valencia [...] and there are just a few lamps in each street, but they illuminate more" (pedestrian and public transportation user, forties, P21, FG2).

She also suggested changing the street lighting in the city of Valencia, from "faint" yellow to white lights. The second participant in the conversation answered "It is very important, because it provides more brightness at night" (pedestrian, fifties, P22, FG2).

\subsubsection{Traffic safety}

\subsubsection{Crossing waiting times}

A lot of participants considered long crossing waiting times as unpleasant. However, for a few of them, it can constitute a real deterrent to walking. For example, a male participant, when talking about crossing waiting times, indicated:

- "Sometimes it is an impediment to walking, it slows you down, it slows you down a lot" (pedestrian and public transportation user, forties, P18, FG2).

In addition, one male participant said it is a "fundamental" factor (car user and pedestrian, fifties, P10, FG1). However, for most participants, long crossing waiting times along a route are not a barrier to walking in itself:

- "It would only affect my decision to change my route" (pedestrian and public transportation user, late twenties, P5, FG0).

- "It is not a deterrent to walking; however, it is influential for changing the walking route" (bicycle and public transportation user, late twenties, P3, FG0).

\subsubsection{Crossing density}

A high intersection density may discourage some people to walk. For example, a female indicated:

- "If you are walking but every 50-100 meters you have to stop because there is a crossing... damn!" (car user and pedestrian, fifties, P19, FG2).

She also stated that this was a reason for driving the car for some short trips. 


\subsubsection{Walking facilities}

\subsubsection{Poor walking sidewalks or lack of sidewalks}

One female car user said that sidewalk conditions influence her to walk or not: "For example, if the sidewalks are not wide enough and comfortable to walk, I would stop walking [...] For comfort and for safety, because some streets are so narrow [...]". (car user and pedestrian, late twenties, P7, FG0).

Apart from safety from crime, one male used to walking for transportation identifies the lack of sidewalks as the most important deterrent to walking: "I just need a sidewalk, of 1.5 meters or similar" (pedestrian and public transportation user, forties, P18, FG2).

\subsubsection{Aesthetics}

\subsubsection{Smell}

One participant in FG0 said:

- 'If it smells very, very badly, I don't like it...if it's ugly it does not influence me much, the same if there is much noise, but with smell during 10 minutes, I can't stand it" (late twenties, pedestrian and public transport user, P4, FG0).

\subsubsection{Convenience and other perceptions}

\subsubsection{Available car parking at destination}

The availability of car parking at destination of the trip is a common deterrent to walking for short trips for habitual car users (6/8 car users). Two women said:

- "The only thing that would make me walk to the University would be the lack of car parking [...]. And in a short trip to another place, if there is no car parking, despite bad weather, I prefer to walk." (early thirties, car user, P6, FG0).

- "In my case, for a short trip, if I had car parking at destination, I would drive" (40-50, car user, P8, FG1).

Another male participant confirmed that the presence of parking when he visits the doctor would encourage him to drive:

- "Despite the fact that the doctor is within walking distance, I would still use the car as long as I can park" (car user and pedestrian, fifties, P9, FG1).

\subsubsection{Hills}

One female participant spontaneously pointed to the slope of streets as a factor deterrent to walking for transportation. 
- "Valencia is a flat city, but in the place where I spend the summer, there are very short distances but with an important slope, therefore, many times I decide to take the car." (pedestrian and car user, forties, P14, FG2).

Another participant added: "Valencia it is a perfect city (for walking)", referring to the flat topography of the city.

\subsection{Secondary factors}

\subsubsection{Pleasant}

\subsubsection{Safety from crime}

Few participants stated that cleanliness in the streets contribute to their safety perception. It is important to note that "cleanliness" has been included in two themes: safety from crime and aesthetics. When this factor appeared in a conversation, the criterion for including it in the group of safety from crime was that the participant explicitly stated that a clean street contributed to her/his feeling of safety from crime or that it was mentioned while talking about this topic.

\subsubsection{Traffic safety}

Other factors making the walking route more pleasant include walking along pedestrian zones, which was reported by a lot of participants. Pedestrian areas can be an influential factor for walking route choice, as a male participant stated when a picture of a square near his residence was shown:

- "Of all the possible routes, this is the one I like the most, not only because it is the shortest, but also because it is a bit more friendly due to it is a pedestrian zone" (pedestrian and public transportation user, late twenties, P5, FG0).

Some participants mentioned the separation of sidewalks from cycle lanes, separation of sidewalks from traffic at bridges and pedestrian countdown at traffic signals. A few referred to audible pedestrian traffic signals to be convenient.

\subsubsection{Walking facilities}

Wide sidewalks were reported by almost all participants. When shown Figure 1a, one male participant said:

- "The sidewalks are narrow, they don't encourage you to walk" (car user, forties, P13, FG1).

Another participant said "sidewalks should be wide, continuous [...]" (pedestrian and public transportation user, forties, P18, FG2) 
When Figure 1d (Avenida del Puerto, 26 meters wide) was shown in the pilot focus group, some participants stated they would change their route to walk down a smaller parallel street, with less traffic. However, one male participant said:

- "I don't think I would change my walking route. I wouldn't walk down a narrower street parallel to this, because the sidewalks here are quite wide [...]". (bicycle user and public transportation user, late twenties, P3, FG0).

A few participants mentioned accessibility and ramps for the disabled, good quality of the sidewalks and presence of shades trees in summer.

\subsubsection{Aesthetics}

Almost all participants indicated that the presence of green elements contributes to a pleasant walking experience. Some participants referred to the presence of trees and greenery as a criterion for the walking route choice. One male participant said:

- "If I can choose, I prefer a walking route with more vegetation; it encourages you more, there is more oxygen and pleases the eye" (pedestrian and public transportation user, forties, P18, FG2).

Another male indicated that he would choose a longer path to a place to be able to walk down the old riverbed of the city of Valencia (transformed into a big garden):

- "Even if the walking route is longer, it is more pleasant walking down the old river basin than walking along the shortest path in streets and sidewalks" (bicycle user and public transportation user, late twenties, P3, FG0).

A lot of participants mentioned an attractive architecture as a pleasant factor while walking. Some participants reported the presence of people (lively area), interesting views, cleanliness, shops, and natural light. Some participants also considered that the presence of benches makes the environment more attractive, one participant said:

- "Benches, either you use them or not, they are part of a set" (car user and pedestrian, fifties, P9, FG1).

A few mentioned a good property maintenance, variety of colors and shapes, homogeneity, criteria and order, low buildings, other urban furniture and graffiti. 
4.2.1.5. Convenience and other perceptions

Walking along open and wide spaces was pleasant for a few participants.

\subsubsection{Unpleasant}

\subsubsection{Safety from crime}

A few participants said that graffiti, closed shops, presence of vagrants, crossing bridges at night, and vacant lots increase their feeling of insecurity.

\subsubsection{Traffic safety}

For almost all participants, high traffic volume contributes to an unpleasant walking experience. A lot of participants talked about long crossing waiting times, bicycle and car users' inappropriate behavior. Some mentioned a high number of lanes, poor coordination between adjacent pedestrian traffic lights to cross avenues and roundabouts, high traffic speed, crossing points with bike lanes, high intersection density, and pedestrian crossings with possibility of turning vehicles. Few participants mentioned a high number of lanes to cross and pedestrian crossings at roundabouts.

A lot of participants considered unpleasant walking down car-oriented avenues, with many lanes and noise from traffic. However, some avenues were seen as more walkable and pleasant. For example, in FG2, almost all participants agreed that walking down wide avenues divided by a green pedestrian boulevard was more pleasant. One female participant said:

- "We are talking about avenues with a green pedestrian area in the middle where you can walk, and despite the traffic, they seem to reduce noise levels" (pedestrian and car user, forties, P17, FG2).

It is also important to mention that a poor coordination between adjacent pedestrian traffic lights to cross avenues and roundabouts was indicated by some participants. When talking about an avenue in Valencia with three adjacent pedestrian traffic lights (Figure 2), some participants said:

- "You have to wait two times because of the traffic lights configuration, two stops $[\ldots]$ it is a lot of waiting time, this is what makes me change my walking route" (pedestrian and public transportation user, late twenties, P5, FG0).

- "The time needed to cross the avenue is incredible, pedestrian traffic lights are not designed for a person to cross walking at normal speed, it is very annoying" (car user and pedestrian, late twenties, P7, FG0). 


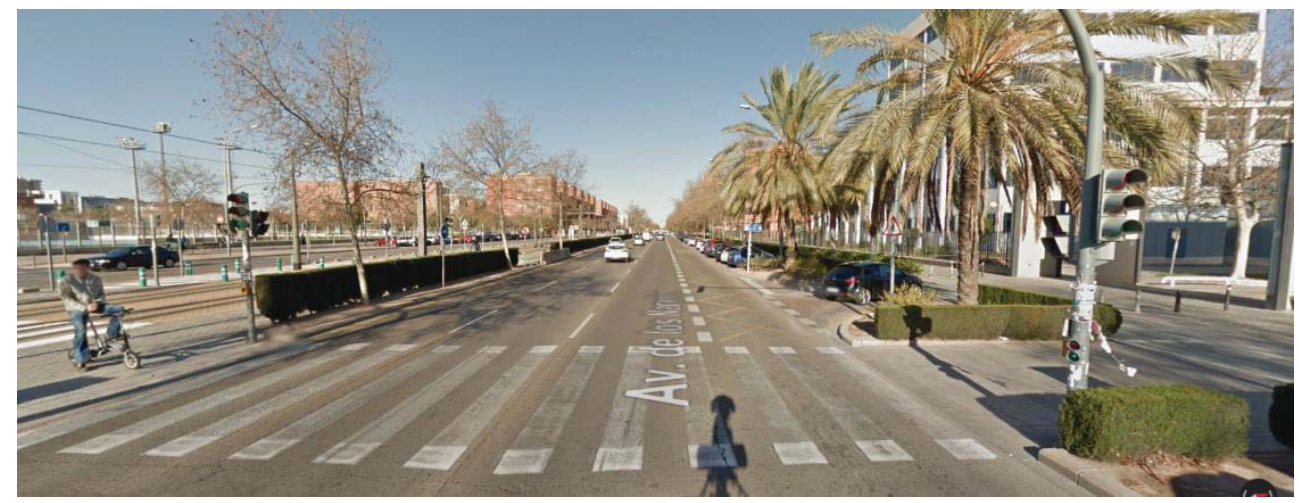

Figure 2- Photograph of Avenida de los Naranjos: it has a section of 70 meters, with 4 traffic lanes in each direction and a tram lane in the middle. Source: Google Street View (accessed on $20^{\text {th }}$ October 2014).

Additionally, the street width was reported by a lot of participants. Some of them appreciated "narrow streets" but not "too narrow". Others referred to wide streets as pleasant. However, some respondents considered unpleasant "too wide avenues".

\subsubsection{Walking facilities}

Factors contributing to an unpleasant walking experience for a lot of participants were the presence of obstacles on sidewalks like parked cars, etc. Sidewalk cafes and bollards were also physical obstacles on sidewalks for some participants. Wide sidewalks can be perceived narrow and unpleasant when pedestrians find obstacles on them:

- "The amount of obstacles....sometimes sidewalks are wide but they get narrower because of the sidewalk cafes, trees and so on, a wide sidewalk gets narrower" (pedestrian and bicycle user, fifties, P16, FG1).

- "There are bollards, bar terraces, bus stops, and a lot of people" (pedestrian, fifties, Participant 12-P12, Focus Group 1-FG1)

One female respondent said that obstacles on sidewalks, when present, should always be placed at the same side of the sidewalk:

- "If there are obstacles, you should know where they are usually placed, they should be in the same position [...] if there are flowerpot stands, all should be on the same side of the sidewalk" (car user and pedestrian, fifties, P19, FG2).

\subsubsection{Aesthetics}

Traffic noise is an unpleasant aesthetic factor to walking for transportation as a lot of participants mentioned. Some participants revealed that it is also a relevant factor for walking route choice. For example: 
- "If you can walk down pedestrian streets, the route is more pleasant..if there are streets with less traffic noise, it is also more pleasant" (pedestrian and bicycle user, fifties, P16, FG1).

- "If I could I would (always) choose the most relaxing route, the quietest" (pedestrian and car user, forties, P17, FG2).

When shown Figure 1d (Avenida del Puerto, 26 meters wide), two participants said they would choose a parallel walking route to the avenue. For example, one of them said:

- "Before walking down here I would walk down a smaller parallel street to this avenue, here there is a lot of traffic, a lot of noise" (pedestrian and public transportation user, late twenties, $\mathrm{P} 4, \mathrm{FG} 0$ ).

On the other hand, three participants mentioned they would not choose a parallel walking route. For example, one of them said:

- "It's not an attractive avenue for me but I would not divert my route, in the picture it seems more unpleasant than it actually is...because of the amount of cars and the number of traffic lanes, because it looks more like an urban highway" (car user and pedestrian, late twenties, P7, FG0).

After showing participants some photographs, a lot of them remarked the lack of green elements as an unpleasant factor. For example, "there is not even one tree" (40-50, pedestrian and public transportation user, P15, FG1) or "there is nothing green" (40-50, public transportation user and car user, P8, FG2). Smell or pollution and dog fouling were mentioned by some participants. Few participants talked about the presence of continuous walls, animals and a bad garbage system.

\subsubsection{Convenience and other perceptions}

A few participants mentioned other factors contributing to an unpleasant walking experience, such as high pedestrian volumes. Very long avenues were also seen as endless by a few participants, increasing their perception of walking route length.

\subsection{Combination of factors}

Although a few factors separately constitute barriers for walking for transportation, our findings also point to the combination of factors that discourage some participants.

\subsubsection{Feeling of insecurity}

The perception of safety from crime may be influenced by a lot of factors that in combination constitute a deterrent to walking for transportation. Some participants identified the "feeling of insecurity" as the only barrier to walking:

- "Yes, the feeling of insecurity at night would be a barrier to walking, otherwise, I think I would walk to a place". (pedestrian and car user, forties, P14, FG1). 
- "What would stop me walking and choose another travel mode? I think it is the feeling of insecurity... Or very special weather conditions, but normally just a few things would deter me from walking for a short trip that I usually undertake walking". (car user and pedestrian, fifties, P9, FG1)

Further research is necessary to determine which combination of factors related to safety from crime inhibits pedestrian activity.

4.3.2. Walking along or crossing large avenues with a high traffic density

A habitual female car user said that the route to a place was an important condition to decide to walk, meaning car-oriented streets can be an impediment to walking for transportation for her:

- "If it is along large avenues with many cars that would not encourage me to walk" (car user, early thirties, P6, FG0).

In FG2, two habitual car users answered affirmatively to the question, "any of those things from the built environment that you don't like, like walking along avenues, the need to cross very wide avenues, can make you say 'I'm not going to walk, I'll take the car"?.

\subsubsection{Route crossing two large roundabouts and a bridge}

A participant referred to a short walking route between two shopping malls (figure 3):

- "If you have to go from Aqua Mall to El Saler Mall, you have to cross a roundabout and all the avenues...it's terrible. Sometimes, [...] I say (to her husband)...no! forget about it, we will take the car" (pedestrian and car user, forties, P17, FG2).

She and her husband referred to the long waiting time to cross the roundabouts due to the poor coordination among traffic lights. One habitual female car user replied: "I think I have never walked for that trip" (car user, fifties, P23, FG2). Other participants, who habitually walk for short trips, agreed the route to be very time-consuming. However, when asked if they would choose not to walk, they said "No, definitely". 


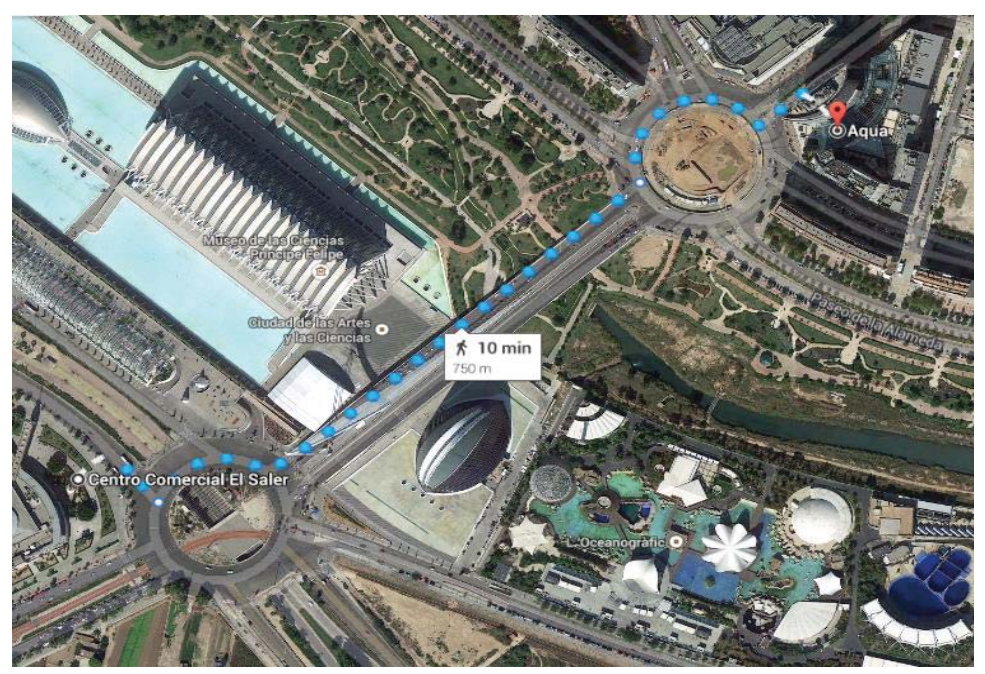

Figure 3- Aerial view of the walking route between two malls in the city of Valencia. Google Maps estimates it is a 10 min walk $\left(750 \mathrm{~m}\right.$ long). Source: Google Street View (accessed on $20^{\text {th }}$ October 2014).

\subsubsection{Route crossing one large roundabout}

When shown two pictures of different roundabouts in FG2, one participant pointed to an example of a large roundabout in Valencia he had to cross recently (Figure 4). Many participants agreed with him on the difficulty of crossing it. They referred to a high intersection density with a poor coordination among adjacent traffic signals.
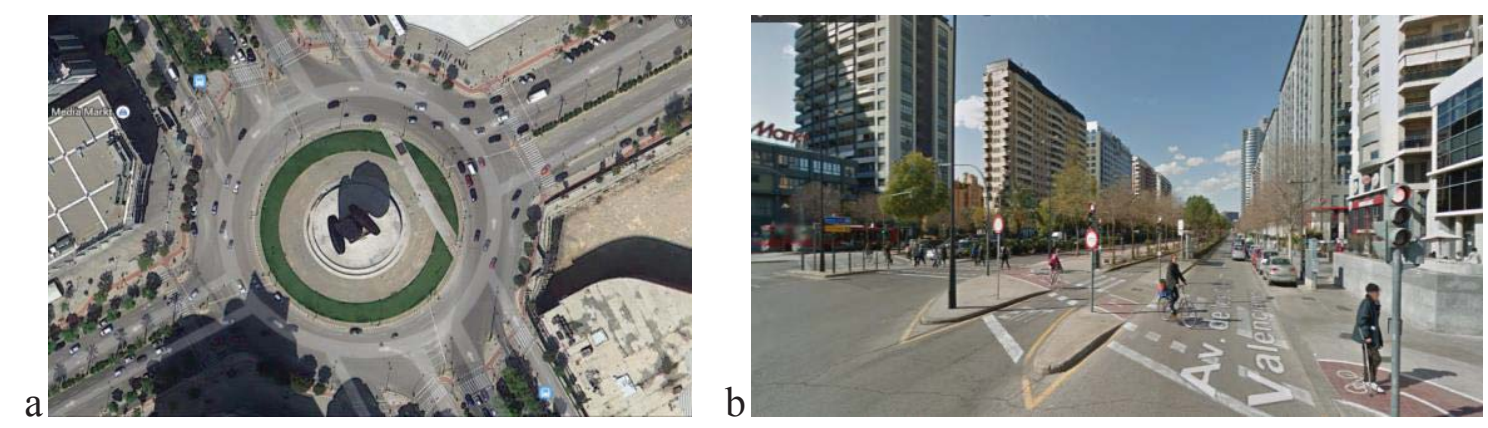

Figure 4. Roundabout in Valencia. Figure 4a. Aerial view of the roundabout: in NW direction, Avenida de las Cortes Valencianas (111 m wide, 7 traffic lanes in each direction), in NE direction, Carrer de la Safor (70 m wide, 5 traffic lanes in each direction). Figure 4b. NW section of Avenida de las Cortes Valencianas. Source: Google Street View (accessed on $20^{\text {th }}$ October 2014).

Participants were asked if crossing roundabouts similar to the one they were talking about could be an impediment to walking for transportation. Three participants answered "yes", including one habitual car user and one habitual pedestrian. 


\section{Discussion}

In all focus groups, it was observed that only a few built environmental factors were barriers to walking for short trips when walking is considered a feasible transportation option (without carrying heavy goods and optimum weather). Among them, safety from crime seems to be the most important deterrent to walking, particularly at night. These results are in line with other studies concluding that a sense of safety from crime encourages walking in adults (Cao et al., 2009; Craig et al., 2002; among others). However, there are important gender differences in the perception of safety from crime: for all female the feeling of insecurity constitutes a barrier to walking, while only some male stated to be fearful to walk.

A lot of respondents reported a poor street lighting to be very influencing in their feelings of insecurity at night, and thus, in the decision to walk or not for transportation. For some respondents, the presence of other people was important. Other studies have also reported the contribution of street lighting to the feeling of safety from crime when walking (Craig et al., 2002; Kelly et al., 2011; Pain et al., 2006; among others). Boyce et al. (2000) also found that the lighting provided is a major factor in determining people's perception of safety at night. A few respondents in FG2 referred to the street lighting color, and agreed that white LED lighting increased their perception of safety compared to yellow light. This is in line with Knight (2010) who found that people perceive areas illuminated with white light to be brighter, safer and more comfortable than the same neighborhoods illuminated with yellow light.

Few attributes related to traffic safety are barriers to walking for short trips. First, long crossing waiting times are perceived as unpleasant by a lot of participants. However, a few participants consider long crossing waiting times as an impediment to walking. Second, routes with high crossing densities were also seen as barriers by some respondents. Thus, a convenient design of pedestrian crossings (waiting times, intersection density) should be provided to encourage walking and make this active travel mode more attractive against private car for short trips. This result is in contrast to prior research suggesting that a good street connectivity (high crossing density), among other factors, encourages walking (Greenwald \& Boarnet, 2001; Kelly et al., 2011; among others). This difference is explained because in our focus groups, crossing density was always referred to as an unpleasant factor linked to pedestrian crossings with traffic lights, where the waiting time to cross is an inconvenience. In line with our finding, Kim et al. (2014) found that a higher intersection density is negatively associated with the level of pedestrian satisfaction. Similarly, Guo \& Loo (2013) studied pedestrian route choice and found that non-chosen routes had, among other factors, more street crossings. Other implications from our findings suggest that in future studies on walking for transportation, the variable of street connectivity should be linked to the density of pedestrian traffic signals: high street connectivity and high density of traffic signals may be deterrents to walking, while high street connectivity and low density of traffic signals may be facilitators to walking. 
Concerning walking facilities, poor sidewalks or the lack of them would deter a few participants from walking. In fact, for a few participants used to walking for transportation, poor sidewalks or the lack of them, together with the feeling of insecurity at night, were mentioned to be the only deterrents. Convenience related factors can also be barriers to walking for transportation. For example, the availability of car parking at destination of a short trip is a very important barrier to walking as stated by almost all habitual car users. Walton \& Sunseri (2006) also found that the convenience of parking at the station induces park-and-ride demand within the $1000 \mathrm{~m}$ radius despite the option to walking. The presence of hills is not an issue in the region of Valencia because of its flat topography.

Other attributes of the built environment, referred to as secondary factors in this study, seem to have an influence in the perception of a pleasant walking experience and the walking route choice. Almost all participants mentioned the presence of green elements and wide sidewalks as pleasant, and high traffic volumes as unpleasant. The presence of green elements and low traffic volumes has largely been related to walking in literature (see Appendix A). However, sidewalk width is a micro-scale factor that very few studies have reported to be positively linked to walking. Our findings suggest that walking along streets with wide sidewalks is highly appreciated and a criterion for pedestrian route choice. This is in line with Tight et al. (2004) and Kelly et al. (2011). However, in our study, two participants reported sufficiently wide sidewalks to be necessary when walking for transportation. Thus, narrow sidewalks may act as barriers to walking. Similarly, Cervero \& Koclelman (1997) found that the probability of walking or cycling for non-work trips increased in neighborhoods with a higher average sidewalk width. More recently, Kamargianni \& Polydoropoulou (2012) found wide pavements significantly affect the choice of walking for transportation.

The presence of obstacles on sidewalks is a very unpleasant secondary factor when walking as reported by most participants. Additionally, some microscale attributes like sidewalk cafes and fixed bollards are also seen as obstacles on sidewalks for some respondents. While the existing literature indicates outdoor dining areas and sidewalk cafes encourage walking for transportation (Alfonzo, 2005; Lovasi et al., 2013), our findings show these elements can make walking less comfortable when sidewalks are not wide enough. Thus, a better regulation of sidewalks cafes is required by local authorities, avoiding sidewalks with many bar terraces and allowing a wide sidewalk for pedestrians. Also, fixed bollards are perceived as unexpected physical obstacles when walking by some participants, so their presence and design to prevent parking on sidewalks should be reconsidered.

Secondary traffic safety factors also emerged in the focus groups. Some participants agreed that pedestrian countdown at traffic signals is more comfortable when crossing and a few referred to audible traffic signals. These elements are convenient in an aging society. Some studies indicated that older adults complain about 
insufficient time to traverse intersections (Lockett et al., 2005; Michael et al., 2006; Nathan et al., 2013).

Some combination of built environmental factors can constitute barriers for transport-related walking. For example, the perception of safety from crime may be influenced by a lot of factors that in combination constitute a deterrent to walking for transportation. Other examples: a female car user stated that main avenues with high traffic density do not encourage her to walk; two habitual car users mentioned crossing wide avenues as an impediment to walking for some trips; and a habitual walker for transportation said she sometimes prefers to take the car for a particular short trip between two malls in the city of Valencia where she has to cross two large roundabouts and a bridge. In another example given by participants, the combination of long waiting times to cross and a high intersection density in a big roundabout was an impediment to walking as stated by a few participants.

Further research is required to determine if secondary factors can constitute, in combination with other factors, barriers to walking for transportation. Kelly et al. (2011) also found that the experience of pedestrians is influenced by the cumulative impact of multiple interactions in the pedestrian environment and some are more important to others. Cauwenberg et al. (2012) found that some factors might influence walking for transportation stronger than others, thus, the anticipated positive influence of certain factors (e.g. the presence of trees and high-quality sidewalks) might be outweighed by the presence of a negative factor (e.g. busy traffic). In addition, Sallis et al. (2009) reported that the presence of at least four favorable environmental factors is required to find a significant relationship with physical activity. The combination of attributes as determinants to walking route choice should also be considered. In this line, Guo \& Loo (2013) suggested that in walking route choice, pedestrians often make trade-offs among various route attributes; may not look for the shortest path, the minimum crossing path, or the least noisy path, but a combination of the three.

Pedestrian-oriented and quiet streets are preferred for walking than car-oriented streets with high traffic volumes and number of lanes. These factors seemed to influence pedestrian route choice for a lot of participants, and constitute a barrier to walking for a few of them (mainly drivers). Further research is required to confirm these findings, and also provide evidence of the more pleasant perception of avenues divided by a green pedestrian boulevard.

\section{Conclusions}

This study is the first using focus groups to identify factors of the built environment influencing walking for transportation in adults with a high level of detail and attention to micro-scale attributes. The use of focus groups not only helped to confirm the influence of environmental factors already found in the literature, but also allowed the identification of new attributes involved. Two groups of built environmental factors 
have been identified, according to their importance on influencing walking for short trips: real barriers to walking and secondary factors related to the walking experience. The identification of the relative importance of each factor provides valuable information for policy makers and planners to consider which attributes of the built environment should be improved first.

When referring to barriers to walking for transportation, both drivers and walkers are aware of them. In all focus groups, it was observed that only a few factors were barriers to walking for participants who usually walk for short trips. Among them, safety from crime seems to be the most important deterrent to walking. However, there are differences in the perceptions of safety according to gender: for all female the feeling of insecurity constitutes a barrier to walking, and only for some male it is a deterrent. A poor street lighting and the absence of people are major barriers at night. Many habitual car users are tempted to use their cars when faced with short trips and there is parking at destination. Results also suggest that infrastructures such as major avenues or roundabouts with several adjacent pedestrian traffic signals with poor coordination between them, can act as barriers to walking. Almost all participants mentioned secondary factors like wide sidewalks, the presence of trees, and low traffic volume roads as pleasant. Sidewalk width is a built environment factor that very few studies associate to walking. Our findings suggest that this micro-scale factor may not only influence pedestrian route choice but also to be a deterrent to walking for a short trip if sidewalks are not wide enough, as a few participants stated. Focus groups also revealed a result not found in the literature: sidewalk cafes and bollards were described as physical obstacles on sidewalks by some participants.

\section{Limitations and future research}

The current study has some limitations. First, focus group participants in the pilot group were known by the moderator and also, some of the participants knew each other, which might have introduced biases in the data due to the lack of anonymity. However, all respondents in the pilot group revealed to be comfortable in the final satisfaction questionnaire and the issue of anonymity was not mentioned by them, reducing the ways in which researchers represent themselves and the interpretations made by focus group participants of the social class background, race, sexuality, etc. The importance of this issue depends on the sensitivity of the topic discussed (Hopkins, 2007). In our case, the moderator is a young female researcher from a town close to Valencia, and she is a habitual car user. To reduce the bias related to the positionality of the moderator, the discussion guide was agreed with the second author of this paper and the research assistant, and her travel behavior and opinions were not revealed in the focus groups. Third, the qualitative approach used makes it difficult to distinguish whether some results may be explained by confounding factors not taken into account, e.g. the 
working status of the participants or the number of cars in the household. A quantitative approach would help to identify all possible confounding factors.

More research is required to delimit barriers and secondary factors to walking for transportation at an individual level, as the perception of a factor as a barrier or secondary factor also depends on demographic and socioeconomic attributes of the respondent (gender, age, socioeconomic status, etc.). Future studies will also determine if secondary factors can constitute, in combination with other factors, barriers to walking for transportation. Additionally, future research should concentrate on pedestrian signal timing, traditionally approached from a safety perspective in literature, but with little attention to its influence on travel mode choice for short trips. To confirm the findings of this study, an online survey will be designed and launched in the city of Valencia using a quantitative approach. Finally, to understand how barriers to walking differ across regions, two new focus groups were organized in another city in Spain (Granada).

\section{Ankowledgements}

We would like to thank the Spanish Ministry of Science and Innovation for funding the research project PEATON-TRA2011-27415. Furthermore, we would also like to thank the participants in the study and Pablo García-Garcés for his assistance with the focus groups.

\section{References}

Ajuntament de València. Padrón de habitantes 2013. Municipios del área metropolitana de Valencia. (2013a).<http://www.valencia.es/ayuntamiento/estadistica.nsf/vDocumentosTituloAux/F5C5449D9 D300604C1257A0F003B9948?OpenDocument\&bdOrigen=ayuntamiento\%2Festadistica.nsf\&idapo yo=21970E9CDEBAD520C12574040038DAE9\&lang=1> (accessed 13.10.14).

Ajuntament de València. Plan de Movilidad Urbana Sostenible de Valencia. (2013b). $<$ http://www.valencia.es/ayuntamiento/trafico.nsf/vDocumentosTituloAux/13E8AC560711B1ADC 1257C5B0041648A? OpenDocument\&bdOrigen=ayuntamiento $\% 2$ Ftrafico.nsf\&idapoyo=\&lang $=1$ \&nivel $=6>$ (accessed 13.10.14).

Alfonzo, M. A. (2005). To walk or not to walk? The hierarchy of walking needs.Environment and Behavior, 37(6), 808-836.

Asbury, J. E. (1995). Overview of focus group research. Qualitative health research, 5(4), 414-420.

Attride-Stirling, J. (2001). Thematic networks: an analytic tool for qualitative research. Qualitative research, 1(3), 385-405.

Badland, H. M., \& Schofield, G. M. (2005). The built environment and transport-related physical activity: what we do and do not know. Journal of Physical Activity \& Health, 2(4).

Bassett, D., Pucher, J., Buehler, R., Thompson, D., Crouter, S. Walking, cycling, and obesity rates in Europe, North America, and Australia. Journal of Physical Activity \& Health 5, pp. 795-814 (2008).

Boyce, P. R., Eklund, N. H., Hamilton, B. J., \& Bruno, L. D. (2000). Perceptions of safety at night in different lighting conditions. Lighting Research and Technology, 32(2), 79-91.

Braun, V., \& Clarke, V. (2006). Using thematic analysis in psychology.Qualitative research in psychology, 3(2), 77-101.

Cao, X., Handy, S. L., \& Mokhtarian, P. L. (2006). The influences of the built environment and residential self-selection on pedestrian behavior: evidence from Austin, TX. Transportation, 33(1), 1-20. http://dx.doi.org/10.1007/s11116-005-7027-2. 
Cao, X. J., Mokhtarian, P. L., \& Handy, S. L. (2009). The relationship between the built environment and nonwork travel: A case study of Northern California.Transportation Research Part A: Policy and Practice, 43(5), 548-559. http://dx.doi.org/10.1016/j.tra.2009.02.001.

Cervero, R., \& Kockelman, K. (1997). Travel demand and the 3Ds: density, diversity, and design. Transportation Research Part D: Transport and Environment, 2(3), 199-219.

Clark, A. F., \& Scott, D. M. (2013). Does the social environment influence active travel? An investigation of walking in Hamilton, Canada. Journal of Transport Geography, 31, 278-285.

Clark, A. F., Scott, D. M., \& Yiannakoulias, N. (2014). Examining the relationship between active travel, weather, and the built environment: a multilevel approach using a GPS-enhanced dataset. Transportation, 41(2), 325-338. http://dx.doi.org/10.1007/s11116-013-9476-3.

Craig, C. L., Brownson, R. C., Cragg, S. E., \& Dunn, A. L. (2002). Exploring the effect of the environment on physical activity: a study examining walking to work. American journal of preventive medicine, 23(2), 36-43. http://dx.doi.org/10.1016/S0749-3797(02)00472-5.

Davison KK, Lawson CT. (2006). Do attributes in the physical environment influence children's physical activity? A review of the literature. International Journal of Behavioral Nutrition and Physical Activity, 3:19. http://dx.doi.org/10.1186/1479-5868-3-19.

European Commission - EC. White Paper. Roadmap to a Single European Transport Area- Towards a competitive and resource efficient transport system [COM(2011)144]. Publications Office of the European Union, Luxembourg (2011).

Ewing, R., \& Handy, S. (2009). Measuring the unmeasurable: Urban design qualities related to walkability. Journal of Urban Design, 14(1), 65-84. http://dx.doi.org/10.1080/13574800802451155.

Flick, U. (2014). An introduction to qualitative research. Sage.

Forward, S. (1998). Modes of transport on short journeys: attitudes and behaviour of the inhabitants of Gothenburg. VTI rapport, (437).

Foster, S., Giles-Corti, B., \& Knuiman, M. (2012). Does fear of crime discourage walkers? A socialecological exploration of fear as a deterrent to walking. Environment and Behavior, DOI: 10.1177/0013916512465176

Frank, L. D., Saelens, B. E., Powell, K. E., \& Chapman, J. E. (2007). Stepping towards causation: do built environments or neighborhood and travel preferences explain physical activity, driving, and obesity?. Social science $\quad \& \quad$ medicine,65(9), $\quad 1898-1914$. http://dx.doi.org/10.1016/j.socscimed.2007.05.053.

Gallagher, N. A., Gretebeck, K. A., Robinson, J. C., Torres, E. R., Murphy, S. L., \& Martyn, K. K. (2010). Neighborhood factors relevant for walking in older, urban, African American adults. Journal of aging and physical activity, 18(1), 99-115.

Giles-Corti, B., \& Donovan, R. J. (2002). Socioeconomic status differences in recreational physical activity levels and real and perceived access to a supportive physical environment. Preventive medicine, 35(6), 601-611.

Grant, T. L., Edwards, N., Sveistrup, H., Andrew, C., \& Egan, M. (2010). Inequitable walking conditions among older people: examining the interrelationship of neighbourhood socio-economic status and urban form using a comparative case study. BMC public health, 10(1), 677.

Greenwald, M. J., \& Boarnet, M. G. (2001). Built environment as determinant of walking behavior: Analyzing nonwork pedestrian travel in Portland, Oregon.Transportation Research Record: Journal of the Transportation Research Board, 1780(1), 33-41.

Guo, Z., \& Loo, B. P. (2013). Pedestrian environment and route choice: evidence from New York City and Hong Kong. Journal of transport geography,28,124-136. http://dx.doi.org/10.1016/j.trangeo.2012.11.013

Handy, S. L., \& Clifton, K. J. (2001). Local shopping as a strategy for reducing automobile travel. Transportation, 28(4), 317-346.

Hodgson, F. C., Page, M., \& Tight, M. R. (2004). A review of factors which influence pedestrian use of the streets: Task 1 report for an EPSRC funded project on measuring pedestrian accessibility.

Hoehner, C. M., Brennan Ramirez, L. K., Elliott, M. B., Handy, S. L., \& Brownson, R. C. (2005). Perceived and objective environmental measures and physical activity among urban adults. American journal of preventive medicine,28(2), 105-116.

Hof, T. (2010). TNO Report: A literature review of individual, perceived physical and social environmental factors related to walking. TNO Defense, Security and Safety.

Hopkins, P. E. (2007). Thinking critically and creatively about focus groups.Area, 39(4), 528-535.

Kamargianni, M., \& Polydoropoulou, A. (2013). Hybrid choice model to investigate effects of teenagers' attitudes toward walking and cycling on mode choice behavior. Transportation Research Record: Journal of the Transportation Research Board, 2382(1), 151-161. 
Kaparias, I., Bell, M. G., Miri, A., Chan, C., \& Mount, B. (2012). Analysing the perceptions of pedestrians and drivers to shared space. Transportation research part F: traffic psychology and behaviour, 15(3), 297-310.

Kelly, C. E., Tight, M. R., Hodgson, F. C., \& Page, M. W. (2011). A comparison of three methods for assessing the walkability of the pedestrian environment. Journal of Transport Geography, 19(6), 1500-1508. http://dx.doi.org/10.1016/j.jtrangeo.2010.08.001.

Kim, S., \& Ulfarsson, G. F. (2008). Curbing automobile use for sustainable transportation: analysis of mode choice on short home-based trips.Transportation, 35(6), 723-737.

Kim, S., Park, S., \& Lee, J. S. (2014). Meso-or micro-scale? Environmental factors influencing pedestrian satisfaction. Transportation Research Part D: Transport and Environment, 30, 10-20. http://dx.doi.org/10.1016/j.trd.2014.05.005.

Knight, C. (2010). Field surveys of the effect of lamp spectrum on the perception of safety and comfort at night. Lighting Research and Technology, 42(3), 313-329.

Koh, P. P., \& Wong, Y. D. (2013). Comparing pedestrians' needs and behaviours in different land use environments. Journal of transport geography, 26, 43-50. http://dx.doi.org/10.1016/j.jtrangeo.2012.08.012.

Krueger RA, Morgan DL: Developing questions for focus groups: focus group kit 3. 1994, 3

Krueger RA \& Casey MA (2000) Focus Groups: A Practical Guide for Applied Research, 3rd ed. Thousand Oaks, CA: Sage Publications.

Lake, A. A., \& Townshend, T. G. (2013). Exploring the built environment, physical activity and related behaviours of young people attending school, college and those not in employment. Journal of public health, 35(1), 57-66. doi: 10.1093/pubmed/fds059.

Lee, C., Zhu, X., Yoon, J., \& Varni, J. W. (2013). Beyond distance: Children's school travel mode choice. Annals of Behavioral Medicine, 45(1), 55-67. Doi: 10.1007/s12160-012-9432-z.

Lee, J. S., Nam, J., \& Lee, S. S. (2014). Built environment impacts on individual mode choice: An empirical study of the Houston-Galveston metropolitan area.International journal of sustainable transportation, 8(6), 447-470. http://dx.doi.org/10.1080/15568318.2012.716142.

Leslie, E., Saelens, B., Frank, L., Owen, N., Bauman, A., Coffee, N., \& Hugo, G. (2005). Residents' perceptions of walkability attributes in objectively different neighbourhoods: a pilot study. Health \& place, 11(3), 227-236.

Lockett, D., Willis, A., \& Edwards, N. (2005). Through seniors' eyes: an exploratory qualitative study to identify environmental barriers to and facilitators of walking. CJNR (Canadian Journal of Nursing Research), 37(3), 48-65.

Loitz, CC. and Spencer-Cavaliere, N. (2013). Exploring the barriers and facilitators to children's active transportation to and from school from the perspectives of practitioners. Journal of Physical Activity \& Health, 10(8):1128-35.

Lovasi, G. S., Schwartz-Soicher, O., Neckerman, K. M., Konty, K., Kerker, B., Quinn, J., \& Rundle, A. (2013). Aesthetic amenities and safety hazards associated with walking and bicycling for transportation in New York City.Annals of behavioral medicine, 45(1), 76-85. doi: 10.1007/s12160012-9416-z.

Mackett, R. L. (2003). Why do people use their cars for short trips?. Transportation, 30(3), 329-349.

Michael, Y. L., Green, M. K., \& Farquhar, S. A. (2006). Neighborhood design and active aging. Health \& place, 12(4), 734-740.

Middleton, J. (2009). 'Stepping in time': walking, time, and space in the city. Environment and planning. A, 41(8), 1943.

Morgan, D. L. (1996). Focus groups. Annual review of sociology, 129-152.

Morgan, D.L., Krueger, R.A., 1998. Focus Group Kit. Sage Publications, Thousand Oaks, CA.

Nathan, A., Wood, L., \& Giles-Corti, B. (2013). Environmental Factors Associated With Active Living in Retirement Village Residents Findings From an Exploratory Qualitative Enquiry. Research on Aging, 35(4), 459-480. http://dx.doi.org/10.1177/0164027512454886.

Onwuegbuzie, A. J., Dickinson, W. B., Leech, N. L., \& Zoran, A. G. (2009). A qualitative framework for collecting and analyzing data in focus group research. International Journal of Qualitative Methods, 8(3), 1-21.

Owen, N., Humpel, N., Leslie, E., Bauman, A., \& Sallis, J. F. (2004). Understanding environmental influences on walking: review and research agenda. American journal of preventive medicine, 27(1), 67-76.

Pain, R., MacFarlane, R., Turner, K., \& Gill, S. (2006). When, where, if, and but': qualifying GIS and the effect of streetlighting on crime and fear. Environment and Planning A, 38(11), 2055. 
Panter, J., Griffin, S., \& Ogilvie, D. (2014). Active commuting and perceptions of the route environment: A longitudinal analysis. Preventive medicine, 67, 134-140.

Rabiee, F. (2004). Focus-group interview and data analysis. Proceedings of the nutrition society, 63(04), 655-660.

Riessman, C. K. (1993). Narrative Analysis. Newbury Park, CA: Sage.

Rodríguez, D. A., \& Joo, J. (2004). The relationship between non-motorized mode choice and the local physical environment. Transportation Research Part D: Transport and Environment, 9(2), 151-173.

Saelens, B. E., Sallis, J. F., \& Frank, L. D. (2003). Environmental correlates of walking and cycling: findings from the transportation, urban design, and planning literatures. Annals of behavioral medicine, 25(2), 80-91

Saelens, B. E., \& Handy, S. L. (2008). Built environment correlates of walking: a review. Medicine and science in sports and exercise, 40(7 Suppl), S550-66.

Sallis JF, Bowles HR, Bauman A, Ainsworth BE, Bull FC, Craig CL, Sjöström M, De Bourdeaudhuij I, Lefevre J, Matsudo V, Matsudo V, Matsudo S, Macfarlane DJ, Gomez LF, Inoue S, Murase N, Volbekiene V, McLean G, Carr H, Heggebo LK, Tomten H, Bergman P: Neighborhood environments and physical activity among adults in 11 countries. American journal of preventive medicine, 2009, 36(6):484-490.

Schneider, R. J. Theory of Routine Mode Choice Decisions: An Operational Framework to Increase Sustainable Transportation. Transport Policy, Vol. 25, 2013, pp. 128-137.

Shriver, K. (1997). Influence of environmental design on pedestrian travel behavior in four Austin neighborhoods. Transportation Research Record: Journal of the Transportation Research Board, 1578(1), 64-75.

Simons, D., Clarys, P., De Bourdeaudhuij, I., de Geus, B., Vandelanotte, C., \& Deforche, B. (2013). Factors influencing mode of transport in older adolescents: a qualitative study. BMC public health, 13(1), 323. doi:10.1186/1471-2458-13-323.

Singleton, P. A., \& Wang, L. M. (2014). Safety and security in discretionary travel decision-making: A focus on active travel mode and destination choice. To be presented at the $93^{\text {rd }}$ Annual Meeting of the Transportation Research Board, Washington, DC.

Strauss, A. L. (1987). Qualitative analysis for social scientists. Cambridge University Press.

Tight M. R., Kelly C., Hodgson F. C., \& Page M. (2004) Improving pedestrian accessibility and quality of life. 10th World Conference on Transport Research. Istanbul, Turkey. July 4-8, 2004.

Van Cauwenberg, J., Van Holle, V., Simons, D., Deridder, R., Clarys, P., Goubert, L., Nasar, J., Salmon, J., De Bourdeaudhuij,I., \& Deforche, B. (2012). Environmental factors influencing older adults' walking for transportation: a study using walk-along interviews. Int J Behav Nutr Phys Act, 9(1), 85. http://dx.doi.org/10.1186/1479-5868-9-85

Van Dyck, D., Cardon, G., Deforche, B., Sallis, J. F., Owen, N., \& De Bourdeaudhuij, I. (2010). Neighborhood SES and walkability are related to physical activity behavior in Belgian adults. Preventive medicine, 50, S74-S79. doi: 10.1016/j.ypmed.2009.07.027.

Walton, D., \& Sunseri, S. (2007). Impediments to walking as a mode choice. Land Transport New Zealand.

Wang, C., \& Burris, M.A. (1997).Photovoice: Concept, methodology, and use for participatory needs. Health Education \& Behavior 1997; 24:369-387. doi: 10.1177/109019819702400309. 
Appendix A. Built environmental factors associated to walking for transportation in adults

\begin{tabular}{lll}
\hline Factors & Effect & Reference \\
\hline WALKING FACILITIES &
\end{tabular}

Presence of sidewalks

Sidewalk

continuity/uninterrupted

walking routes

Sidewalk surface type

Sidewalk width

Sidewalks

maintenance/quality (cracked or uneven sidewalks, etc.)

Obstacles on sidewalks (parked cars, etc.)

Accesibility/ramps

Shade

Dry surface condition

Rain shelters

Availability of directional signs

TRAFFIC SAFETY

Traffic volume

Traffic speed

Number of lanes /or intersection distance

Availability of crossings

Pedestrian traffic lights

Poor crossing visibility

Insufficient time for crossing intersections
Handy \& Clifton (2001), Craig et al. (2002), Giles-Corti \& Donovan (+) (2002), Rodriguez \& Joo (2004), Leslie et al. (2005), Cao et al., 2009, Singleton \& Wang (2013)

(+) Shriver (1997), Greenwald \& Boarnet (2001), Craig et al. (2002), Pikora et al. (2003) ${ }^{\mathrm{b}}$, Rodriguez \& Joo (2004)

$(+/-) \quad$ Pikora et al. $(2003)^{\mathrm{b}}$

(+) Cervero \& Kockelman (1997), Tight et al. (2004) ${ }^{\mathrm{c}}$, Kelly et al. (2011) $)^{\mathrm{c}}$, Kamargianni \& Polydoropoulou (2012)

Craig et al. (2002), Pikora et al. (2003) $)^{\mathrm{b}}$, Tight et al. (2004) ${ }^{\mathrm{c}}$, (+/-) Hoehner et al. (2005)(-), Leslie et al. (2005), Middleton (2009)a Kelly et al. $(2011)^{\mathrm{c}}$

(-) Forward (1999), Craig et al. (2002), Tight et al. (2004) ${ }^{\mathrm{c}}$

(+) Craig et al. (2002)

(+) Shriver (1997), Cao et al. (2006)

(+) Tight et al. (2004) $)^{\mathrm{c}}$, Kaparias et al. (2012) ${ }^{\mathrm{c}}$

(+) Koh \& Wong $(2013)^{\mathrm{c}}$

(+) Koh \& Wong $(2013)^{\mathrm{c}}$

Cao et al. (2006), Cao et al. (2009), Koh \& Wong (2013) ${ }^{\mathrm{c}}$

Forward (1999), Handy \& Clifton (2001), Craig et al. (2002), Giles(-/+) Corti \& Donovan (2002) (+), Pikora et al. (2003) ${ }^{\mathrm{b}}$, Cao et al. (2006), Middleton (2009) ${ }^{\mathrm{a}}$, Kelly et al. (2011) ${ }^{\mathrm{c}}$, Kaparias et al. (2012) ${ }^{\mathrm{c}}$, Singleton \& Wang (2013)

(-) Handy \& Clifton (2001), Pikora et al. (2003) ${ }^{\mathrm{b}}$, Craig et al. (2002), Tight et al. (2004) $)^{\mathrm{c}}$, Kelly et al. (2011)

(-) Pikora et al. $(2003)^{\mathrm{b}}$

(+) Pikora et al. $(2003)^{\mathrm{b}}$

$(+/-)$ Craig et al. (2002), Pikora et al. (2003) ${ }^{\mathrm{b}}$, Middleton (2009) $)^{\mathrm{a}}(-)$

(-) Kelly et al. $(2011)^{\mathrm{c}}$

(-) Handy \& Clifton (2001) 
Appendix A (continued)

\begin{tabular}{|c|c|c|}
\hline Factors & Effect & Reference \\
\hline \multicolumn{3}{|l|}{ TRAFFIC SAFETY } \\
\hline $\begin{array}{l}\text { No direct route to cross the } \\
\text { road (detours) }\end{array}$ & $(-)$ & Kelly et al. $(2011)^{\mathrm{c}}$ \\
\hline Crossing waiting times & $(-)$ & Middleton (2009) $)^{\mathrm{a}}$ Koh \& Wong $(2013)^{\mathrm{c}}$ \\
\hline Intersection design & & Pikora et al. $(2003)^{b}$ \\
\hline $\begin{array}{l}\text { Traffic calming devices (e.g. } \\
\text { speed bumps) }\end{array}$ & $(+)$ & Singleton \& Wang (2013) \\
\hline Curb ramps & $(-)$ & Singleton \& Wang (2013) \\
\hline Pedestrian zones & $(+)$ & Pikora et al. $(2003)^{\mathrm{b}}$, Kaparias et al. $(2012)^{\mathrm{c}}$ \\
\hline Separation from traffic & $(+)$ & $\begin{array}{l}\text { Craig et al. (2002), Leslie et al. (2005), Pikora et al. (2003) })^{\mathrm{b}} \text { Kelly } \\
\text { et al. }(2011)^{\mathrm{c}}\end{array}$ \\
\hline Cyclists on sidewalks & $(-)$ & Tight et al. $(2004)^{\mathrm{c}}$, Kelly et al. $(2011)^{\mathrm{c}}$ \\
\hline Traffic signal density & $(+)$ & Cervero \& Kockelman (1997), Singleton \& Wang (2013) \\
\hline Ease of crossing & $(+)$ & $\begin{array}{l}\text { Greenwald \& Boarnet (2001), Tight et al. (2004) })^{\text {c }} \text {, Panter et al. } \\
(2014)\end{array}$ \\
\hline SAFETY FROM CRIME & $(+)$ & $\begin{array}{l}\text { Forward (1999), Cao et al. (2009), Koh \& Wong }(2013)^{\mathrm{c}} \text {, } \\
\text { Foster et al. (2012) }\end{array}$ \\
\hline Street lighting & $(+)$ & $\begin{array}{l}\text { Craig et al. (2002), Pikora et al. }(2003)^{b} \text {, Tight et al. }(2004)^{c} \text {, Pain et } \\
\text { al. }(2006)^{a} \text {, Kelly et al. }(2011)^{c} \text {, Kaparias et al. }(2012)^{c}\end{array}$ \\
\hline Presence of people & $(+)$ & Craig et al. (2002) \\
\hline $\begin{array}{l}\text { Burglary, } \quad \text { vandalism, } \\
\text { homicide rate }\end{array}$ & $(-)$ & Craig et al. (2002), Pain et al. (2006) a, Lovasi et al. (2013) \\
\hline Property maintenance & $(+)$ & Craig et al. (2002) \\
\hline Passive surveillance & $(+)$ & Pikora et al. $(2003)^{\mathrm{b}}$ \\
\hline Escape routes & $(+)$ & Craig et al. (2002) \\
\hline Graffiti & $(-)$ & Craig et al. (2002), Tight et al. (2004) ${ }^{\mathrm{c}}$, Hoehner et al. (2005) \\
\hline Anti-crime measures & $(-)$ & Singleton \& Wang (2013) \\
\hline AESTHETICS & $(+)$ & Attractiveness (Cao et al. 2009) \\
\hline Interesting views & $(+)$ & Shriver (1997), Koh \& Wong $(2013)^{\mathrm{c}}$ \\
\hline Street cleanliness & $(+)$ & $\begin{array}{l}\text { Pikora et al. }(2003)^{\mathrm{b}} \text {, Tight et al. }(2004)^{\mathrm{c}} \text {, Hoehner et al. (2005), } \\
\text { Middleton }(2009)^{\mathrm{a}} \text {, Kelly et al. }(2011)^{\mathrm{c}}\end{array}$ \\
\hline Dog fouling & $(-)$ & Tight et al. $(2004)^{c}$ \\
\hline Benches & $(+)$ & Shriver (1997) \\
\hline $\begin{array}{l}\text { Other street furniture (litter } \\
\text { bins, etc.) }\end{array}$ & $(+)$ & Kelly et al. (2011) \\
\hline Unattended animals & $(-)$ & Tight et al. $(2004)^{\mathrm{c}}$ \\
\hline $\begin{array}{l}\text { Green elements (trees, parks, } \\
\text { etc.) }\end{array}$ & $(+)$ & $\begin{array}{l}\text { Cervero \& Kockelman (1997), Shriver (1997), Middleton (2009) }{ }^{\text {a }} \text {, } \\
\text { Kaparias et al. }(2012)^{\mathrm{c}} \text {, Koh \& Wong }(2013)^{\mathrm{c}}\end{array}$ \\
\hline
\end{tabular}




\section{Appendix A (continued)}

Factors Effect Reference

\section{AESTHETICS}

\begin{tabular}{|c|c|c|}
\hline Noise & $(-)$ & Handy \& Clifton (2001), Kelly et al. (2011) ${ }^{\mathrm{c}}$ \\
\hline Smell/pollution & $(-)$ & Pikora et al. $(2003)^{b}$, Kelly et al. $(2011)^{c}$ \\
\hline $\begin{array}{l}\text { Presence of people (social } \\
\text { contacts or lively area) }\end{array}$ & $(+)$ & $\begin{array}{l}\text { Shriver (1997), Hoehner et al. (2005), Cao et al. (2009), Clark \& } \\
\text { Scott (2013) }\end{array}$ \\
\hline $\begin{array}{l}\text { verload of stimulus (visual } \\
\text { ad auditory stimuli) }\end{array}$ & $(-)$ & Craig et al. (2002) \\
\hline
\end{tabular}

\section{CONVENIENCE}

\begin{tabular}{|c|c|c|}
\hline Car parking & $(-)$ & $\begin{array}{l}\text { Cervero \& Kockelman (1997), Handy \& Clifton (2001), Pikora et al. } \\
(2003)^{\mathrm{b}} \text {, Leslie et al. (2005), Walton \& Sunseri (2006) }\end{array}$ \\
\hline Hills/slopes & $(-)$ & $\begin{array}{l}\text { Craig et al. (2002), Rodriguez \& Joo (2004), Greenwald \& Boarnet } \\
\text { (2001), Leslie et al. (2005), Koh \& Wong (2013) }\end{array}$ \\
\hline High pedestrian volumes & $(-/+)$ & Kaparias et al. $(2012)(+)^{\mathrm{c}}$, Koh \& Wong $(2013)^{\mathrm{c}}$ \\
\hline $\mathrm{ACCE}$ & & Cao et al., 2009, Hoehner et al. (2005) \\
\hline Public transport & $(+)$ & $\begin{array}{l}\text { Shriver (1997), Craig et al. (2002), Pikora et al. (2003) })^{\mathrm{b}} \text {, Hoehner et } \\
\text { al. (2005), Koh \& Wong (2013)(-) }{ }^{\mathrm{c}}\end{array}$ \\
\hline $\begin{array}{l}\text { Presence of shops, stores } \\
\text { within walking distance or } \\
\text { along the route }\end{array}$ & $(+)$ & $\begin{array}{l}\text { Shriver (1997), Handy \& Clifton (2001), Giles-Corti \& Donovan } \\
\text { (2002), Pikora et al. (2003) })^{\mathrm{b}} \text {, Tight et al. (2004) } \text {, Cao et al. (2006), } \\
\text { Leslie et al. (2005), Koh \& Wong }(2013)^{\mathrm{c}}\end{array}$ \\
\hline Sidewalk cafes & $(+)$ & Lovasi et al. (2013) \\
\hline
\end{tabular}

\section{LAND USE}

\begin{tabular}{|c|c|c|}
\hline $\begin{array}{l}\text { Population density } \\
\text { residential density }\end{array}$ & $(+)$ & $\begin{array}{l}\text { Cervero \& Kockelman (1997), Leslie et al. (2005), Frank et al. } \\
\text { (2007), Greenwald \& Boarnet (2001), Kim \& Ulfarsson (2008), Van } \\
\text { Dyck et al. (2010), Singleton \& Wang (2013), Clark et al. (2014) }\end{array}$ \\
\hline Retail presence & $(+)$ & $\begin{array}{l}\text { Frank et al. (2007), Greenwald \& Boarnet (2001), Kim \& Ulfarsson } \\
\text { (2008), Singleton \& Wang (2012) }\end{array}$ \\
\hline Land use mix & $(+)$ & $\begin{array}{l}\text { Cervero \& Kockelman (1997), Shriver (1997), Craig et al. (2002), } \\
\text { Leslie et al. (2005), Frank et al. (2007), Cao et al. (2009), Van Dyck } \\
\text { et al. (2010), Clark \& Scott (2013) }\end{array}$ \\
\hline Net residential connectivity & $(+)$ & Frank et al. (2007) \\
\hline $\begin{array}{l}\text { Street connectivity } \\
\text { (crossing/intersection } \\
\text { density) }\end{array}$ & $(+/-)$ & $\begin{array}{l}\text { Cervero \& } \text { Kockelman (1997), Shriver (1997), Handy \& Clifton } \\
(2001) \text {, Greenwald \& Boarnet (2001), Leslie et al. (2005), Frank et al. } \\
(2007) \text {, Van Dyck et al. (2010), Kelly et al. }(2011)^{c} \text {, } \\
\text { Koh \& Wong }(2013)(-)^{c}\end{array}$ \\
\hline Neighborhood type & & $\begin{array}{l}\text { Shriver (1997), Frank et al. (2007), Cao et al. (2009), } \\
\text { Kim \& Ulfarsson (2008) }\end{array}$ \\
\hline
\end{tabular}

$(+)$ positive effect on walking for transportation, (-) negative effect

${ }^{\text {a }}$ Reported in a qualitative study, ${ }^{b}$ Delphi study (panel of experts), ${ }^{\mathrm{c} I m p o r t a n c e}$ survey (participants rate the importance of factors to walking), otherwise, quantitative study finding a significant correlation of the built environmental factor and walking for transportation, whether the attribute is objectively or subjectively assessed 